\title{
Molecular Effects of Spaceflight in the Mouse Eye after Space Shuttle Mission STS-135
}

\author{
Corey A. Theriot ${ }^{1}$ and Susana B. Zanello ${ }^{2}$ \\ ${ }^{I}$ Department of Preventive Medicine and Community Health, University of Texas Medical Branch, Galveston, \\ TX; ${ }^{2}$ Division of Space Life Sciences, Universities Space Research Association, Houston, TX
}

\begin{abstract}
Exposure to long-duration microgravity leads to ocular changes in astronauts, manifested by a variety of signs and symptoms during spaceflight that in some cases persist after return to Earth. These morphological and functional changes are only partly understood and are of occupational health relevance. To investigate further into the molecular basis of the changes occurring in ocular tissue upon exposure to spaceflight, eyes were collected from male C57BL/6 mice flown on STS-135 (FLT) on landing day or from their ground control counterparts maintained at similar conditions within the Animal Enclosure Module (AEM). One eye was fixed for histological sectioning while the contralateral eye was dissected to isolate the retina for gene expression profiling. 8-hydroxy-deoxyguanosine (8OHdG) staining showed a statistically significant increase in the inner nuclear layer of FLT samples
\end{abstract}

Key words: Retina; Mouse; Microgravity; Oxidative Stress; Microarray

Correspondence to: Susana Zanello

Universities Space Research Association Lyndon B. Johnson Space Center

Division of Space Life Sciences

2101 NASA Parkway

Mail Code SK

Houston, TX 77058

Telephone: 281-244-6779

Fax: 281-483-2888

E-mail: susana.b.zanello@nasa.gov compared to AEM. Gene expression analysis in isolated retina identified 139 differentially expressed genes in FLT compared to AEM control samples. The genes affected were mainly involved in pathways and processes of endoplasmic reticulum (ER) stress, inflammation, neuronal and glial cell loss, axonal degeneration, and herpes virus activation. These results suggest a concerted change in gene expression in the retina of mice flown in space, possibly leading to retinal damage, degeneration, and remodeling.

\section{INTRODUCTION}

Space exploration involves challenges for an extended human presence. The space environment exposes the human body to a unique combination of physical and psychological stressors. Most noteworthy are the effects of microgravity and high charge/high energy (HZE) particle radiation with a potential for hypoxia (in off-nominal situations), occasional hyperoxia, dietary restrictions, and possible nutritional deficiencies as significant hazardous confounding factors (Sonnenfeld et al., 2003; Taibbi et al., 2013; Taylor et al., 2013; Sides et al., 2005; Mader et al., 1999; Planel et al., 1989; Reitz et al., 2009; Cucinotta et al., 2001; Cucinotta et al., 2008). Microgravity induces cephalad fluid shifts and physical unloading, leading to deleterious effects such as muscle atrophy, loss of bone mass, cardiovascular alterations, postflight orthostatic intolerance, and immunosuppression (Pietsch et al., 2011; Sundaresan and Pellis, 2009; Blaber et al., 2013). More recently, ocular changes 
associated with spaceflight have been reported in astronauts exhibiting alterations in near visual acuity and other ocular-based signs and symptoms (Alexander et al., 2012). These medical data describe evidence of optic disc edema, choroidal folds and posterior globe flattening, hyperoptic shift in vision, optic nerve sheath distension, and in some cases, optic nerve kinking and empty sella (Kramer et al., 2012; Mader et al., 2011), possibly associated with intracranial pressure increase. Identifying causative factors and investigating microgravity's influence as a source of stress for the eye have acquired importance.

Previous basic research investigating the effects of spaceflight on eye structures and general ocular health is scarce and limited to basic histopathology on space-flown animal models (Marshall-Bowman et al., 2013). Neonatal rats flown for nine days onboard the Space Shuttle mission STS-72 displayed clear evidence of retinal degeneration (Tombran-Tink and Barnstable, 2006). In another study, adult rats flown onboard Russian Cosmos satellites for approximately 14 days exhibited cellular swelling in the retina and retinal disruption (Philpott et al., 1980).

Recently, our group investigated the effects of spaceflight on the eyes of mice flown onboard Space Shuttle mission STS-133 and, for the first time, reported molecular and cellular changes correlating to the histopathologic outcomes (Zanello et al., 2013). Flight samples from that study stained positive for $\beta$-amyloid and glial fibrillary acidic protein (GAFP) in the optic nerve. Retina from mice flown on STS-133 also showed increased levels of 8-hydroxy-2'-deoxyguanosine $(8 \mathrm{OHdG})$, an oxidized form of guanosine that serves as a standard biomarker of oxidative DNA damage, and of caspase-3 immunoreactivity, suggesting an early step both in the extrinsic (death ligand) and intrinsic (mitochondria) apoptosis pathway. In addition, upregulated levels of oxidative and cellular stress response genes were detected. Herein, we report the findings of a subsequent animal experiment onboard STS-135 in which we expanded the molecular aspects of the impact of spaceflight on retinal biology by performing differential gene expression profiling between mice flown onboard STS-135 and their ground control counterparts.

\section{MATERIALS AND METHODS}

\section{Animals}

This work is the result of a tissue sharing effort that utilized specimens collected from a parent animal experiment onboard STS-135. Animal procedures were approved by the NASA Ames Research Center and Kennedy Space Center institutional animal care and use committees. Mice were flown onboard STS-135 that lifted off at 11:29 a.m. EDT on July 8, 2011 and landed at 5:57 a.m. on July 21, 2011. The mission duration was 12 days, 18 hours, and 28 minutes.

Male 9 to 11 week-old C57BL/6 mice were assigned to one of two experimental groups: Flight (FLT) and Animal Enclosure Module (AEM) ground controls. Both eyes from three animals for each group $(n=3)$ were used in this study, one for gene expression analysis and the other for histology. The flight animals were housed in AEMs identical to the ground controls, and our analysis focuses on the comparison between these two conditions. The AEM is a selfcontained habitat that provides ventilation, waste management, food, water, and controlled lighting (Naidu et al., 1995), and has previously been used in experiments studying rodent biology during spaceflight. The AEM was located in the middeck locker of the Space Shuttle, and the temperature was set at 3 to $8^{\circ} \mathrm{C}$ above the environmental middeck temperature. Lighting of 14 lux was set to a 12 hour day/12 hour night cycle for both FLT and AEM habitats.

After euthanasia at day one of landing, one eye of each mouse was enucleated and fixed for histologic examination. The contralateral eye was placed in RNA preservative (RNAlater ${ }^{\circledR}$ ) until further dissection, which was performed by making an incision by scalpel to separate the posterior eye cup, removing the lens and vitreous and carefully scraping the retina. The retina was then placed again in RNAlater ${ }^{\circledR}$ and processed for gene expression profiling by microarray analysis as described below.

\section{Materials}

A 4\% paraformaldehyde-based histologic fixative was obtained from Excalibur Pathology, Inc., Oklahoma City, OK. Goat polyclonal antibody to 8-hydroxy-2'-deoxyguanosine (8- 
OHdG) (ab10802) and rabbit polyclonal antibody to activated caspase-3 (ab52181) were purchased from Abcam Inc., Cambridge, MA. Paraffin embedding and histological sectioning were contracted from Excalibur Pathology. RNA isolation reagents were purchased from Qiagen Inc., Valencia, CA and BioRad, Hercules, CA. Tissue samples were assigned a different number for immunohistochemistry evaluation and gene profiling in order to perform a masked analysis.

\section{Histology and Immunohistochemistry}

Fixed eyes were paraffin embedded, sectioned at $5 \mu \mathrm{m}$ thickness, and stained with standard hematoxylin-eosin (H\&E) for histologic examination. Two immunohistologic stains were performed: $8 \mathrm{OHdG}$ to detect oxidative-related DNA damage and activated caspase-3 to study apoptosis. For $8 \mathrm{OHdG}$ and caspase-3 staining, sections were equilibrated in water after deparaffinization and treated sequentially in 3\% hydrogen peroxide, $1 \%$ acetic acid, and 2.5\% serum (Vector Labs, Burlingame, CA) before incubating with the diluted primary antibody for either two hours at room temperature or overnight at $4^{\circ} \mathrm{C}$. After washing, the specimens were incubated with Vector ImmPress detection kit, corresponding to the primary antibody's host and counterstained with hematoxylin.

\section{Caspase-3 Detection}

A qualitative approach was used to compare apoptosis in the retina. Activated caspase-3 positive cells were identified for the retinal ganglion cell (RGC) layer in a retina section for each sample. The histologic sections were cut in the proximity of the optic nerve head for better comparison.

\section{OHdG Immunoreactivity Quantification}

Estimation of the $8 \mathrm{OHdG}$ immunoreactivity was done using ImageJ software (masked for specific study groups) on $8 \mathrm{OHdG}$ stained slides. Briefly, digital color images of the retina were processed using NIH ImageJ ver.1.68 (NIH) and converted to an 8-bit inverted grayscale image for analysis. Regions of interest were selected from each retinal section, corresponding to the RGC layer, inner nuclear layer (INL), and outer nuclear layer (ONL), as well as nearby areas without immunoreactivity for background measurements.
Five sections were analyzed for each sample, for which the mean density per unit area (minus mean background density) was measured. A 2-tailed $t$ test with an alpha of $p<0.05$ was used to determine statistical significance.

\section{Gene Expression Analysis}

Mouse retina was microdissected and isolated from the rest of the eye and then placed again in RNAlater ${ }^{\circledR}$. Total RNA was then isolated from the retina using the AllPrep DNA/RNA Micro kit (Qiagen, Valencia, CA) and analyzed for quality using an Agilent 2100 Bioanalyzer (Agilent Technologies, Inc., Santa Clara, CA). All samples used reported a RNA Integrity Number (RIN) $>6.0$ and were confirmed to have 2 sharp bands/peaks representing the $28 \mathrm{~s}$ and $18 \mathrm{~s}$ RNA. Some variability in the RIN among samples was observed, presumably due to a handling delay in sample processing that derived from reasons out of our control, which caused the samples to remain in RNAlater ${ }^{\circledR}$ at $4^{\circ} \mathrm{C}$ for four months before dissection of the retina. Microarray gene expression analysis was performed at the University of Texas Medical Branch (UTMB) at Galveston Molecular Genomics Core using Affymetrix Mouse $430 \quad 2.0 \quad$ GeneChip (Affymetrix, Inc., Santa Clara, CA) with Affymetrix Expression Console and Transcriptome Analysis Console for secondary analysis. An Ingenuity iReport (Ingenuity Systems, Redwood City, CA) was then generated for canonical pathway identification. Two-way (gene and sample) hierarchical cluster analysis was performed on log-transformed, median-centered, and normalized signals from the FLT and AEM ground control samples. Normalized expression values were obtained using the Robust Multichip Analysis (RMA) algorithm. Results were visualized with the Transcriptome Analysis Console software 1.0.0.234 (Affymetrix, Inc.) using a cut-off $P$ value of 0.05 and a minimum fold-change of 1.5.

\section{RESULTS}

\section{Caspase-3 Analysis of Retina Specimens}

Caspase-3 immunoreactivity was moderate and localized mostly in some RGCs. Caspase-3 positive cells in the RGC layer showed intense cytoplasmic and neurite staining, particularly in 
the FLT samples. Representative images are present in Figure 1 (Panels A and B) with arrows pointing to localized Caspase staining. Higher magnification views are shown for the AEM (panel C) and FLT (panel D) in Figure 1. We observed signs of retinal disruption at the level of the photoreceptors and INL, with vacuolization and cell swelling.

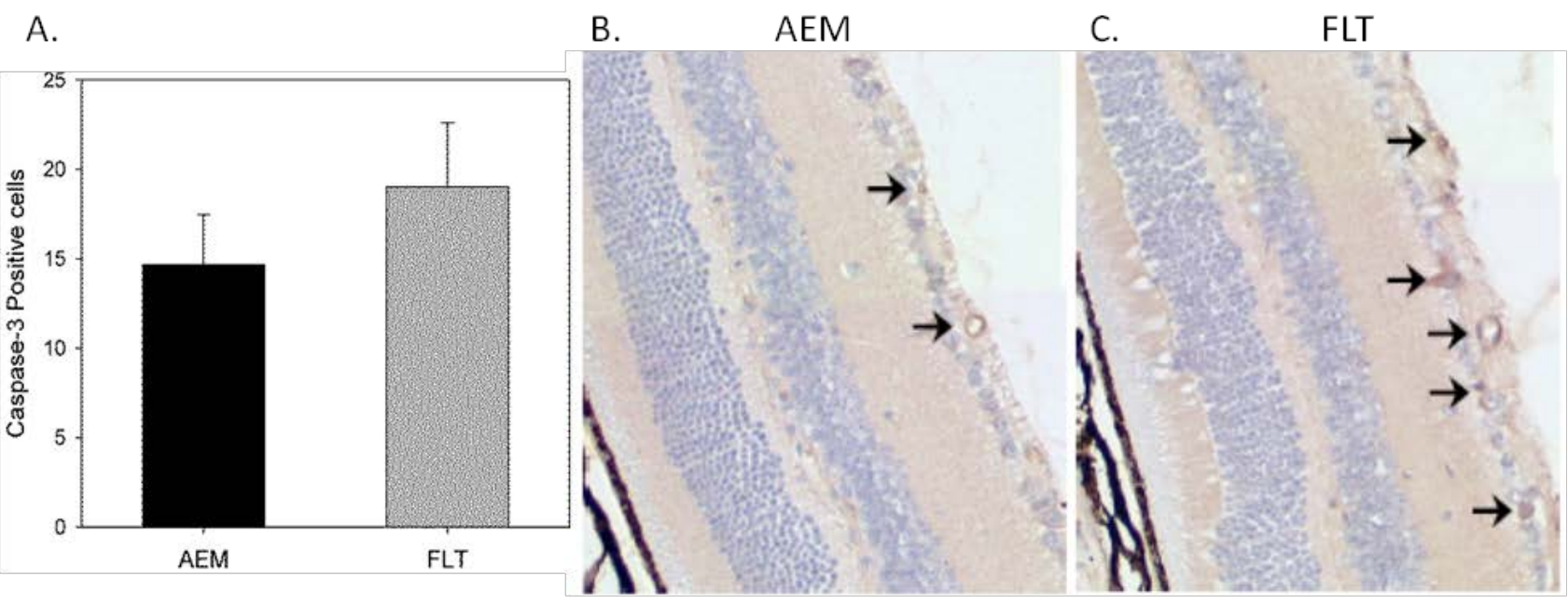

Figure 1. Activated caspase-3 immunoreactivity in mouse retina. Representative images of histological sections stained for caspase-3 are presented for AEM ground controls (Panel A) and FLT samples (Panel B). Individual cells staining positive for caspase-3 and undergoing various morphological changes are denoted by arrows $(\rightarrow)$ in Panels $A \&$ B. Panels $C$ and $D$ are higher magnifications of $A$ and B, respectively. Retina cell layers are labeled between Panels $C$ and D as ONL, INL, and RGC.

\section{OHdG Analysis of Retina Specimens}

To quantify oxidative DNA damage in the retina, densitometric quantification of $8 \mathrm{OHdG}$ immunohistochemistry was performed on eye sections ( $\mathrm{n}=3$ /group), as presented in Figure 2. A statistically significant increase in $8 \mathrm{OHdG}$ was detected in the INL between the FLT and AEM ground control groups. $8 \mathrm{OHdG}$ intensity levels were not shown to be statistically different in the ONL and the RGC between FLT samples and AEM ground controls.

\section{Microarray Analysis of Retina Specimens}

Microarray analysis was performed using the Mouse Expression Set 430 microchip, which allows the independent multi-probe detection of over 39,000 transcripts on a single array. Using the analytical parameters specified in the Methods section, 139 differentially expressed genes were identified in FLT retina samples compared to AEM controls (at least 1.5-fold expression change, $P<0.05$ ), of which 107 gene probesets were upregulated and 32 gene probesets were downregulated (Table 1). The 139 differentially expressed genes were analyzed with a 2-way hierarchical cluster analysis and presented in Figure 3. The samples analyzed formed two groups on the horizontal axis, clearly separating the three FLT samples (right three lanes) from the three AEM samples (left three lanes) (Figure 3, Panel B). Figure 3 also shows two examples of downregulated clusters that contain numerous genes involved in transcription regulation and histone maintenance (Panel C).

Relevant gene expression changes were organized and filtered biologically and functionally by pathway analysis tools based on the Ingenuity Knowledge Base, a repository of curated biological interactions and functional annotations. The pathways were generated through the use of Ingenuity ${ }^{\circledR}$ iReport (Ingenuity ${ }^{\circledR}$ Systems, http://www.ingenuity.com) and are summarized in Table 2. 


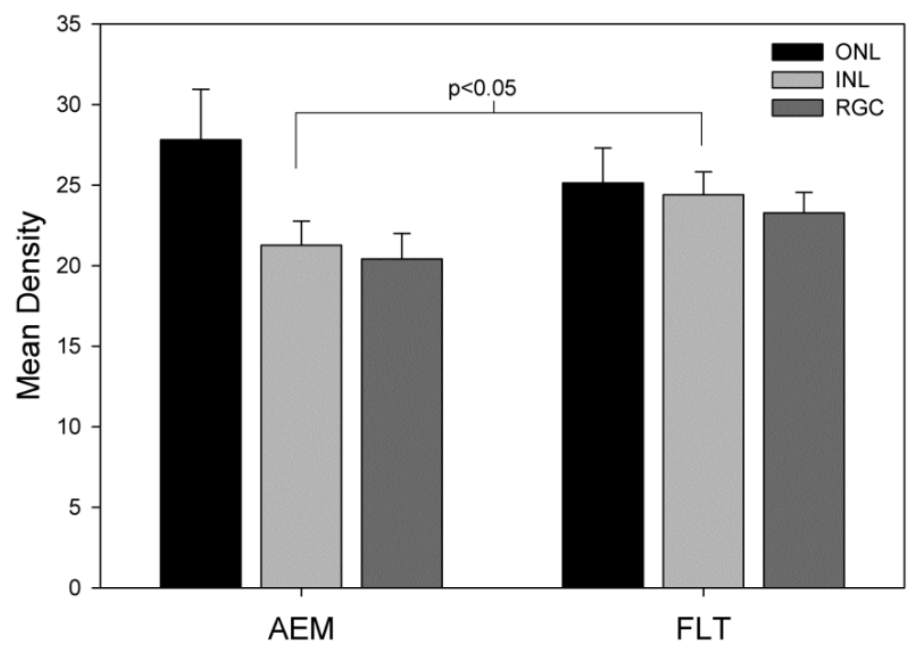

Figure 2. 80HdG immunoreactivity in neuronal retina layers. Each individual neuronal cell layer was analyzed for $80 \mathrm{HdG}$ specific immunostaining intensity. Results shown are mean intensities from analysis of at least 5 sections per sample $(n=3)$ for each group. Statistical significance is noted in the graph.

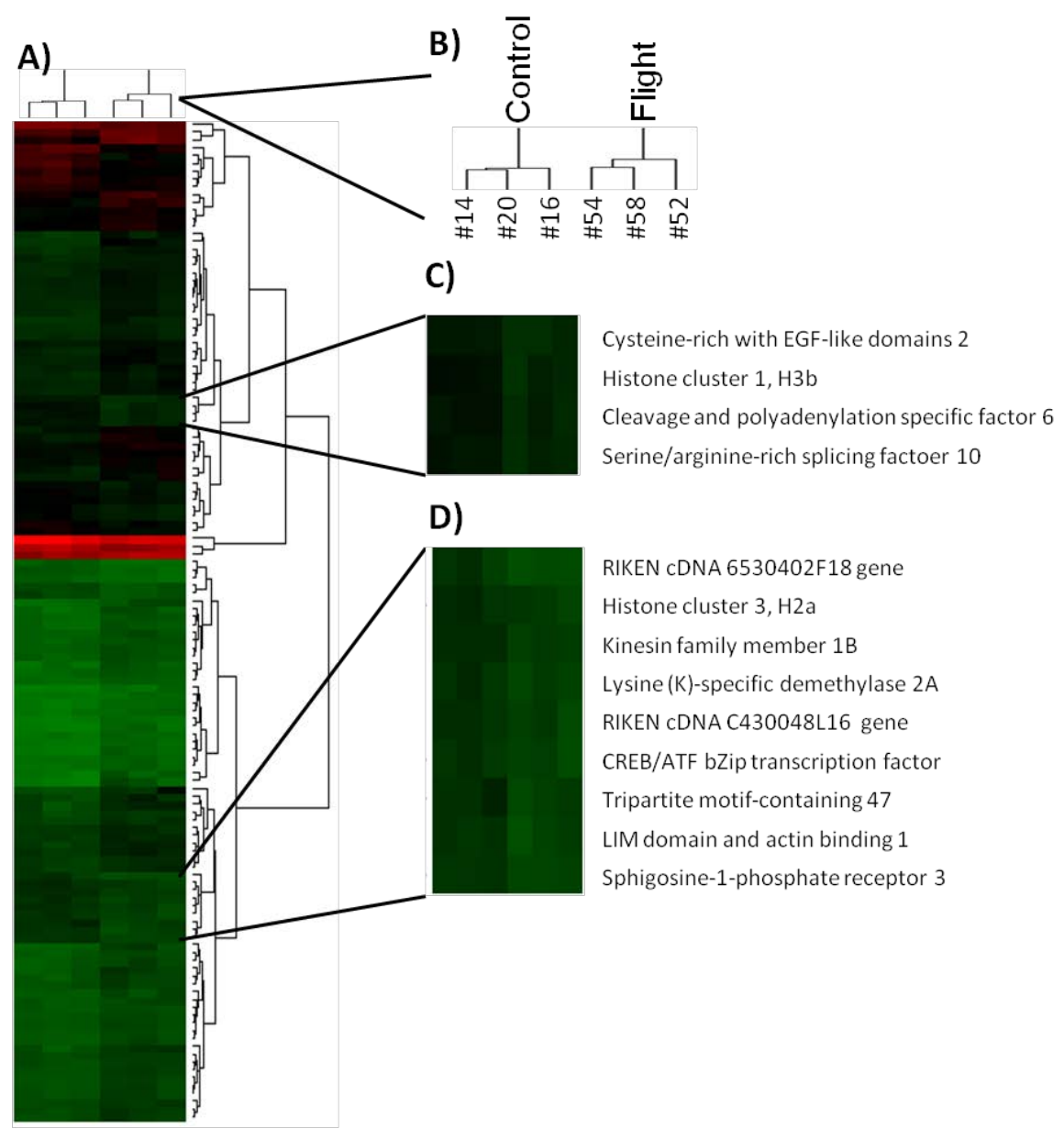

Figure 3. Hierarchical cluster analysis of AEM control and FLT samples using the 139 differentially expressed probesets identified by gene expression profiling. Hierarchical cluster analysis of microarray results of AEM and FLT samples (Panel A). Expanded view of the dendogram showing AEM and FLT sample clustering (Panel B). Expanded view of two representative downregulated gene clusters (Panel C). 
Table 1. Summary of the 139 differentially expressed genes in FLT compared to AEM ground controls. Genes are listed according to fold change and its associated known molecular function.

\begin{tabular}{|c|c|c|}
\hline Symbol: Name & Fold Change & Molecular Function \\
\hline DSP: desmoplakin & 4.01 & other \\
\hline LY6E: lymphocyte antigen 6 complex, locus E & 2.95 & other \\
\hline LCN2: lipocalin 2 & 2.75 & transporter \\
\hline SLC44A2: solute carrier family 44 , member 2 & 2.55 & transporter \\
\hline CIRBP: cold inducible RNA binding protein & 2.48 & translation regulator \\
\hline POU4F1: POU class 4 homeobox 1 & 2.44 & transcription regulator \\
\hline SGMS2: sphingomyelin synthase 2 & 2.36 & enzyme \\
\hline Defb9: defensin beta 9 & 2.36 & other \\
\hline RIPK4: receptor-interacting serine-threonine kinase 4 & 2.32 & kinase \\
\hline RPRD2: regulation of nuclear pre-mRNA domain containing 2 & 2.15 & other \\
\hline PAQR8: progestin and adipoQ receptor family member VIII & 2.04 & other \\
\hline 1700019G17Rik/Cml2: camello-like 2 & 1.99 & other \\
\hline CUL2: cullin 2 & 1.98 & enzyme \\
\hline ALCAM: activated leukocyte cell adhesion molecule & 1.96 & other \\
\hline ZBTB16: zinc finger and BTB domain containing 16 & 1.95 & transcription regulator \\
\hline CLVS1: clavesin 1 & 1.93 & other \\
\hline ZC3H6: zinc finger CCCH-type containing 6 & 1.92 & other \\
\hline B4GALNT1: beta-1,4-N-acetyl-galactosaminyl transferase 1 & 1.92 & enzyme \\
\hline GNA13: guanine nucleotide binding protein ( $\mathrm{G}$ protein), alpha 13 & 1.89 & enzyme \\
\hline CTSH: cathepsin H & 1.87 & peptidase \\
\hline WFS1: Wolfram syndrome 1 & 1.84 & enzyme \\
\hline HNRPDL: heterogeneous nuclear ribonucleoprotein D-like & 1.84 & other \\
\hline PARP12: poly (ADP-ribose) polymerase family, member 12 & 1.83 & other \\
\hline EHD4: EH-domain containing 4 & 1.82 & enzyme \\
\hline ACOT9: acyl-CoA thioesterase 9 & 1.81 & enzyme \\
\hline AGXT2L1: alanine-glyoxylate aminotransferase 2-like 1 & 1.80 & enzyme \\
\hline SH3YL1: SH3 domain containing, Ysc84-like 1 & 1.80 & other \\
\hline 2210403K04Rik: RIKEN cDNA 2210403K04 gene & 1.79 & other \\
\hline INPP1: inositol polyphosphate-1-phosphatase & 1.79 & phosphatase \\
\hline SLC39A4: solute carrier family 39 (zinc transporter), member 4 & 1.79 & transporter \\
\hline ZSCAN21: zinc finger and SCAN domain containing 21 & 1.79 & transcription regulator \\
\hline $\begin{array}{l}\text { CMAS: cytidine monophosphate N-acetylneuraminic acid } \\
\text { synthetase }\end{array}$ & 1.77 & enzyme \\
\hline KALRN: kalirin, RhoGEF kinase & 1.76 & kinase \\
\hline RUFY2: RUN and FYVE domain containing 2 & 1.76 & other \\
\hline TRIM25: tripartite motif containing 25 & 1.76 & transcription regulator \\
\hline ANGPTL4: angiopoietin-like 4 & 1.74 & other \\
\hline $\begin{array}{l}\text { CHST15: carbohydrate ( } \mathrm{N} \text {-acetylgalactosamine 4-sulfate 6-O) } \\
\quad \text { sulfotransferase } 15\end{array}$ & 1.73 & enzyme \\
\hline PEX13: peroxisomal biogenesis factor 13 & 1.72 & transporter \\
\hline MKRN1: makorin ring finger protein 1 & 1.72 & other \\
\hline A2M: alpha-2-macroglobulin & 1.72 & transporter \\
\hline
\end{tabular}


STS-135 Mouse Retina

\begin{tabular}{|c|c|c|}
\hline Symbol: Name & Fold Change & Molecular Function \\
\hline MRPL15: mitochondrial ribosomal protein L15 & 1.71 & other \\
\hline FABP4: fatty acid binding protein 4 , adipocyte & 1.71 & transporter \\
\hline AI451250: expressed sequence AI451250 & 1.69 & other \\
\hline KRT23: keratin 23 (histone deacetylase inducible) & 1.69 & other \\
\hline FKBP5: FK506 binding protein 5 & 1.69 & enzyme \\
\hline FAM194A: family with sequence similarity 194 , member A & 1.66 & other \\
\hline MFSD6: major facilitator superfamily domain containing 6 & 1.66 & other \\
\hline Gm9776: predicted gene 9776 & 1.66 & other \\
\hline $\begin{array}{l}\text { SDR42E1: short chain dehydrogenase/reductase family } 42 \mathrm{E}, \\
\text { member } 1\end{array}$ & 1.66 & enzyme \\
\hline A930041H05Rik: RIKEN cDNA A930041H05 gene & 1.65 & other \\
\hline TXNRD3: thioredoxin reductase 3 & 1.65 & enzyme \\
\hline Pax6os1: Pax6 opposite strand transcript 1 & 1.65 & other \\
\hline $\begin{array}{l}\text { SLC1A1: solute carrier family } 1 \text { (neuronal/epithelial high affinity } \\
\text { glutamate transporter), member } 1\end{array}$ & 1.64 & transporter \\
\hline COL19A1 (includes EG:12823): collagen, type XIX, alpha 1 & 1.63 & other \\
\hline $\begin{array}{l}\text { GPCPD1: glycerophosphocholine phosphodiesterase GDE1 } \\
\text { homolog (S. cerevisiae) }\end{array}$ & 1.62 & other \\
\hline LGI1: leucine-rich, glioma inactivated 1 & 1.62 & other \\
\hline DCXR: dicarbonyl/L-xylulose reductase & 1.62 & enzyme \\
\hline SBSN: suprabasin & 1.62 & other \\
\hline NIPSNAP1: nipsnap homolog 1 (C. elegans) & 1.61 & enzyme \\
\hline SMC6: structural maintenance of chromosomes 6 & 1.61 & other \\
\hline REPS2: RALBP1 associated Eps domain containing 2 & 1.60 & other \\
\hline HIST2H2AA3/HIST2H2AA4: histone cluster 2, H2aa3 & 1.60 & other \\
\hline $\begin{array}{l}\text { CRISPLD2: cysteine-rich secretory protein LCCL domain } \\
\quad \text { containing } 2\end{array}$ & 1.59 & other \\
\hline SORL1: sortilin-related receptor & 1.59 & transporter \\
\hline WWC1: WW and $\mathrm{C} 2$ domain containing 1 & 1.59 & transcription regulator \\
\hline DHCR24: 24-dehydrocholesterol reductase & 1.59 & enzyme \\
\hline ACSL5: acyl-CoA synthetase long-chain family member 5 & 1.59 & enzyme \\
\hline SMOX: spermine oxidase & 1.58 & enzyme \\
\hline $\begin{array}{l}\text { CHCHD7: coiled-coil-helix-coiled-coil-helix domain containing } \\
\quad 7\end{array}$ & 1.58 & other \\
\hline NT5C2: 5'-nucleotidase, cytosolic II & 1.58 & phosphatase \\
\hline CPNE8: copine VIII & 1.58 & other \\
\hline TCTA: T-cell leukemia translocation altered gene & 1.58 & other \\
\hline $\begin{array}{l}\text { PLEKHH1: pleckstrin homology domain containing, family } \mathrm{H} \\
\text { (with MyTH4 domain) member } 1\end{array}$ & 1.57 & other \\
\hline Rbpms: RNA binding protein gene with multiple splicing & 1.57 & transcription regulator \\
\hline TTLL11: tubulin tyrosine ligase-like family, member 11 & 1.57 & other \\
\hline FEM1C: fem-1 homolog c (C. elegans) & 1.57 & transcription regulator \\
\hline PLIN4: perilipin 4 & 1.57 & other \\
\hline CDA: cytidine deaminase & 1.57 & enzyme \\
\hline IFI35: interferon-induced protein 35 & 1.56 & other \\
\hline UGT1A6: UDP glucuronosyltransferase 1 family, polypeptide A6 & 1.56 & enzyme \\
\hline
\end{tabular}




\begin{tabular}{|c|c|c|}
\hline Symbol: Name & Fold Change & Molecular Function \\
\hline D130037M23Rik: RIKEN cDNA D130037M23 gene & 1.56 & other \\
\hline $\begin{array}{l}\text { SLC7A1: solute carrier family } 7 \text { (cationic amino acid transporter, } \\
\text { y+ system), member } 1\end{array}$ & 1.56 & transporter \\
\hline SNRPD3: small nuclear ribonucleoprotein D3 polypeptide 18kDa & 1.55 & other \\
\hline TSC22D3: TSC22 domain family, member 3 & 1.55 & other \\
\hline KAZN: kazrin, periplakin interacting protein & 1.55 & other \\
\hline SH3BP5: SH3-domain binding protein 5 (BTK-associated) & 1.55 & other \\
\hline CHL1: cell adhesion molecule with homology to L1CAM & 1.54 & other \\
\hline HNRNPD: heterogeneous nuclear ribonucleoprotein D & 1.54 & transcription regulator \\
\hline PLIN2: perilipin 2 & 1.54 & other \\
\hline PTGIS: prostaglandin I2 (prostacyclin) synthase & 1.53 & enzyme \\
\hline ARMCX5: armadillo repeat containing, X-linked 5 & 1.53 & other \\
\hline TNFAIP2: tumor necrosis factor, alpha-induced protein 2 & 1.53 & other \\
\hline BRD8: bromodomain containing 8 & 1.53 & transcription regulator \\
\hline BTBD11: BTB (POZ) domain containing 11 & 1.53 & transcription regulator \\
\hline PHYHIP: phytanoyl-CoA 2-hydroxylase interacting protein & 1.53 & other \\
\hline RBM3: RNA binding motif (RNP1, RRM) protein 3 & 1.52 & other \\
\hline HAGHL: hydroxyacylglutathione hydrolase-like & 1.51 & enzyme \\
\hline MARVELD2: MARVEL domain containing 2 & 1.51 & other \\
\hline WWP2: WW domain containing E3 ubiquitin protein ligase 2 & 1.51 & enzyme \\
\hline DIS3: DIS3 mitotic control homolog (S. cerevisiae) & 1.51 & enzyme \\
\hline ZBTB22: zinc finger and BTB domain containing 22 & 1.51 & other \\
\hline CYB561: cytochrome b-561 & 1.51 & enzyme \\
\hline RNF208: ring finger protein 208 & 1.51 & other \\
\hline FAM122B: family with sequence similarity 122B & 1.51 & other \\
\hline UPK3B: uroplakin 3B & 1.51 & other \\
\hline C6orf1 15: chromosome 6 open reading frame 115 & 1.50 & other \\
\hline MARCH7: membrane-associated ring finger $(\mathrm{C} 3 \mathrm{HC} 4) 7$ & 1.50 & other \\
\hline HSPH1: heat shock $105 \mathrm{kDa} / 110 \mathrm{kDa}$ protein 1 & -1.51 & other \\
\hline LOC100505793/SRSF10: serine/arginine-rich splicing factor 10 & -1.51 & other \\
\hline LIMA1: LIM domain and actin binding 1 & -1.53 & other \\
\hline KDM2A: lysine (K)-specific demethylase 2A & -1.53 & other \\
\hline CREBZF: CREB/ATF bZIP transcription factor & -1.54 & transcription regulator \\
\hline CRELD2: cysteine-rich with EGF-like domains 2 & -1.54 & other \\
\hline BCAS2: breast carcinoma amplified sequence 2 & -1.54 & other \\
\hline DYNLL1: dynein, light chain, LC8-type 1 & -1.55 & other \\
\hline BB116930: expressed sequence BB116930 & -1.55 & other \\
\hline SRSF6: serine/arginine-rich splicing factor 6 & -1.56 & other \\
\hline $\begin{array}{l}\text { CHORDC1: cysteine and histidine-rich domain (CHORD) } \\
\text { containing } 1\end{array}$ & -1.57 & other \\
\hline PUM2: pumilio homolog 2 (Drosophila) & -1.59 & other \\
\hline HIST3H2A: histone cluster $3, \mathrm{H} 2 \mathrm{a}$ & -1.61 & other \\
\hline $\begin{array}{l}\text { TRPM1: transient receptor potential cation channel, subfamily M, } \\
\text { member } 1\end{array}$ & -1.62 & ion channel \\
\hline
\end{tabular}




\begin{tabular}{lcl}
\hline \multicolumn{1}{c}{ Symbol: Name } & Fold Change & \multicolumn{1}{c}{ Molecular Function } \\
\hline \hline TRIM47: tripartite motif containing 47 & -1.62 & other \\
4931428L18Rik: RIKEN cDNA 4931428L18 gene & -1.63 & other \\
XBP1 (includes EG:140614): X-box binding protein 1 & -1.65 & transcription regulator \\
HIST1H3A: histone cluster 1, H3a & -1.66 & other \\
HSPA5: heat shock 70kDa protein 5 & -1.69 & enzyme \\
6530402F18Rik: RIKEN cDNA 6530402F18 gene & -1.70 & other \\
ARSI: arylsulfatase family, member I & -1.70 & enzyme \\
NECAB1: N-terminal EF-hand calcium binding protein 1 & -1.73 & other \\
CPSF6: cleavage and polyadenylation specific factor 6, 68kDa & -1.73 & other \\
BTG1: B-cell translocation gene 1, anti-proliferative & -1.74 & transcription regulator \\
HIST2H3C (includes others): histone cluster 2, H3c & -1.79 & other \\
CA8: carbonic anhydrase VIII & -1.79 & enzyme \\
C430048L16Rik/Rbm12b: RIKEN cDNA C430048L16 gene & -1.89 & other \\
TRA2A: transformer 2 alpha homolog (Drosophila) & -2.10 & other \\
MALAT1: metastasis associated lung adenocarcinoma transcript & -2.15 & other \\
1 & & G-protein coupled \\
S1PR3: sphingosine-1-phosphate receptor 3 & -2.26 & receptor \\
SFPQ: splicing factor proline/glutamine-rich & -2.33 & other \\
SLC5A3: solute carrier family 5 (sodium/myo-inositol & -2.64 & transporter \\
cotransporter), member 3 & & \\
\hline
\end{tabular}

Table 2. Potential molecular pathways, processes, and diseases states triggered by spaceflight in the mouse retina.

\begin{tabular}{|c|c|c|}
\hline PATHWAYS & PROCESSES & DISEASES \\
\hline $\begin{array}{l}\text { Endoplasmic Reticulum } \\
\text { (ER) stress }\end{array}$ & $\begin{array}{l}\text { RNA processing (mRNA } \\
\text { splicing) }\end{array}$ & Molecular mechanisms of cancer \\
\hline Pyrimidine metabolism & $\begin{array}{l}\text { Cell death of sensory neurons and } \\
\text { RGC }\end{array}$ & $\begin{array}{l}\text { Neurodegeneration of nerves and } \\
\text { nervous tissue }\end{array}$ \\
\hline $\begin{array}{l}\text { Cytokine production and } \\
\text { signaling (IL-1, IL-6, } \\
\text { IL17) }\end{array}$ & $\begin{array}{l}\text { Apoptosis of microglia and } \\
\text { neuronal cells }\end{array}$ & Degeneration of the optic nerve \\
\hline Sphingosine-1-P signaling & $\begin{array}{l}\text { Stabilization and assembly of } \\
\text { desmosomes }\end{array}$ & Reactivation of herpes virus \\
\hline $\begin{array}{l}\text { Axonal guidance and actin } \\
\text { cytoskeleton }\end{array}$ & Axon branching & \\
\hline
\end{tabular}

\section{DISCUSSION}

Our work explores the possible effects of the spaceflight environment on retinal biology, in an effort to shed light on the confounding factors and processes that may contribute to vision risks in space. Corollary to a previous report on the effects of spaceflight on the retina of $\mathrm{BALB} / \mathrm{cJ}$ mice
(Zanello et al., 2013), we now report results of a similar experiment carried out on C57BL mice onboard STS-135. The main findings in this work demonstrate evidence of increased oxidative stress-DNA damage, histological changes, as well as potential effects of spaceflight on retinal biology based on microarray gene expression profiling. Similar results have been reported by an 
independent group (Mao et al., 2013); however, the gene expression profiling performed in the cited work originated from non-dissected eyes that included all eye tissues and structures. The eye is a complex organ with a heterogeneous tissue composition due to its various structures: sclera, cornea, retina, lens, choroid, retina microvasculature, aqueous humor production, and drainage system. Therefore, gene expression derived from the entire eye globe does not precisely reflect the tissue of origin of the genetic responses. Our work presents, for the first time, comparative whole genome expression profiling of retinas dissected from mice exposed to spaceflight and their ground controls. Even in this case, we must bear in mind that the retina is composed of various cell types from both neural and vascular cellular populations.

A number of activated caspase-3 positive cells were observed, in particular, in the RGC layer of FLT samples, but due to the limitation in the number of sections, our examination was limited to a qualitative comparison. Overall, caspase-3 immunoreactivity in the FLT samples was observed to be localized at moderate levels in the RGC, with light levels seen throughout the photoreceptor inner segments. Of note, cytological alterations in the photoreceptor layer from FLT mice in this study were in line with previous reports in the literature of spaceflight induced damage to the ganglion cell layer and disruption of the plexiform layers and photoreceptors of rat neonates (Tombran-Tink and Barnstable 2006). Quantification of $8 \mathrm{OHdG}$ immunoreactivity showed statistically significant $(P<0.05)$ increase in DNA damage in the INL of FLT mice compared to AEM controls. Similar findings were observed in the previous experiment in $\mathrm{BALB} / \mathrm{cJ}$ mice; however, BALB/cJ mice showed larger damage in the photoreceptor layer upon exposure to spaceflight. The propensity of this strain to develop retinal degeneration due to light (Song et al., 2012; Hadziahmetovic et al., 2012; Whelan and McGinnis 1988; Chang et al., 2002) (and probably other kinds of electromagnetic radiation) may provide an explanation for this difference.

Pathway analysis derived from differential gene expression of microarray data revealed processes related to neuronal and glial cell loss, mechanisms of apoptosis, and ER stress. Evidence supporting these processes included, among others, the downregulation (-1.65 fold FLT vs. AEM) of XBP1, a potent transcription factor involved in the unfolded protein response (UPR). Processing of XBP1 mRNA is an obligate step in the UPR pathway and the IRE1/XBP-1 pathway is required for efficient protein folding, maturation, and degradation in the ER (Calfon et al., 2002; Lee et al., 2002; Sriburi et al., 2004). In addition, Hspa5, a member of the Hsp70 family that also resides in the ER and participates in protein folding, was also downregulated -1.69 fold, in agreement with a possible impairment of the ER stress response, which other studies have linked to increased susceptibility to Alzheimer's disease (Hebert and Molinari 2007; Guzel et al., 2011; Hsu et al., 2008). A result of cellular insults that cause prolonged ER stress include apoptosis through caspase-7-mediated caspase-12 activation and lead to neuronal and glial cell loss (Nakagawa et al., 2000; Szegezdi et al., 2003).

Interestingly, XBP1 is also implicated in processes related to the reactivation of herpes virus (Lawson et al., 2008; Dalton-Griffin et al., 2009; Wilson et al., 2007). It is well known that virus reactivation is a common phenomenon associated with spaceflight, but the mechanisms leading to it are not understood (Brinley et al., 2013; Mehta et al., 2000; Mehta et al., 2004; Stowe et al., 2001). We must bear in mind that the retina is mostly composed of neural cells and that the herpes virus is neurotropic. A putative implication of XBP1 as a transcription factor crucial in the protection against viral reactivation in space is not implied, but could be further investigated to shed some light into possible targets for mitigation against the risk of viral reactivation in space.

Other differentially expressed genes between FLT and AEM retinas suggested pathways of neuronal cell loss and degeneration. SLC1A1, a member of the high-affinity glutamate transporters that play an essential role in transporting glutamate across plasma membranes, was upregulated +1.64 in FLT compared to AEM retinas. In the brain, these transporters are crucial in terminating the postsynaptic action of the neurotransmitter glutamate and in maintaining extracellular glutamate concentrations below neurotoxic levels (Sheldon and Robinson 2007; Deng et al., 2007; Arnold et al., 2006). It has also 
been shown to be involved in RGC death (Martins et al., 2006; Sheldon and Robinson, 2007) and its upregulation in FLT samples may suggest that glutamate level increase may be associated with space environmental factors. Concurrently, the transporter lipocalin 2 (LCN2) showed a marked upregulation of +2.75 fold in the FLT group. LCN2 has been shown in the literature to be related to inflammation in the retina following ischemia-reperfusion injury (Abcouwer et al., 2013) and may serve a similar role in modulating an inflammatory response to spaceflight.

Beta-amyloid deposits have previously been suggested as related to RGC and optic nerve degeneration (Zanello et al., 2013). Alpha-2macroglobulin (A2M) inhibits many proteases, including trypsin, thrombin, and collagenase and is implicated in Alzheimer disease due to its ability to mediate the clearance and degradation of A-beta, the major component of beta-amyloid deposits (Liao et al., 1998; Blacker et al., 1998). Our results show that $\mathrm{A} 2 \mathrm{M}$ was induced +1.72 fold in FLT compared to ground AEM, possibly suggesting the triggering of clearance mechanisms to reduce an increase in any deposits.

The RNA used in this study originated from dissected retina containing a mixed cell type population. While the major representation is of neural cells of various types, it is expected that some relevant genes were represented due to their expression in other retinal cell types. Endothelial cells from the retinal microvasculature are one example. S1PR3 encodes a member of the EDG family of receptors, which are G-protein coupled receptors (Crousillac et al., 2009). This protein has been identified as a functional receptor for sphingosine 1-phosphate and likely contributes to the regulation of angiogenesis and vascular endothelial cell function (Sanchez et al., 2007; Daum et al., 2009). We observed a significant downregulation of -2.26 fold in FLT retinas versus AEM, a change that may suggest vascular remodeling could be taking place in conjunction with some degree of retinal degeneration and neural remodeling and should be investigated in future studies. Changes in the expression of genes related to axonal guidance were also observed in FLT compared to AEM such as GNA13 and KALRN (Lee and Luo, 1999; Mandela et al., 2012), in agreement with the concept of vascular and neural guidance as coordinated processes
(Suchting et al., 2006; Eichmann et al., 2005; Park et al., 2003). A significant upregulation of two key genes implicated in reorganization of the cytoskeleton, cell shape, and cell-cell adhesion by desmosomes, guanine nucleotide binding protein (G protein) alpha 13, and desmoplakin $(+1.89$ and +4.01 fold, respectively) also suggests that remodeling processes were taking placed in the stressed retinas of FLT mice.

In summary, these results bring light to some of the molecular processes taking place in the retina when mice are exposed to spaceflight environmental conditions. While we have highlighted the pathways that may be biologically relevant and correlated with the changes observed in the histomorphology of retinal tissues of animals exposed to spaceflight, this work provides a catalog of differentially expressed genes that can be used to explore various hypotheses related to the pathophysiology of visual alterations in spaceflight and translated to possible ocular implications for human crews in long-duration space exploration missions.

\section{ACKNOWLEDGEMENTS}

This material is based upon work supported by the NASA Human Research Program. The authors wish to thank the UTMB Molecular Genomics Core for their help in conducting analysis of microarray results.

\section{REFERENCES}

Abcouwer SF, Lin CM, Shanmugam S, Muthusamy A, Barber AJ, Antonetti DA (2013) Minocycline prevents retinal inflammation and vascular permeability following ischemia-reperfusion injury. Journal of Neuroinflammation 10: 149

Alexander D, Gibson CR, Hamilton D, Lee S, Mader T, Otto C, Oubre C, Pass AF, Platts $\mathrm{SH}$, Scott JM, Smith SM, Stenger MB, Westby CM, Zanello SB (2012) Evidence report: risk of spaceflight-induced intracranial hypertension and vision alterations. In $N A S A$ Human Research Roadmap

Arnold P, Sicard T, Burroughs E, Richter MA, Kennedy JL (2006) Glutamate transporter gene Slclal associated with obsessivecompulsive disorder. Archives of General Psychiatry 63 (7): 769-776 
Blaber AP, Zuj KA, Goswami N (2013) Cerebrovascular autoregulation: lessons learned from spaceflight research. European Journal of Applied Physiology 113(8): 19091917

Blacker D, Wilcox MA, Laird NM, Rodes L, Horvath SM, Go RCP, Perry R, Watson B, Bassett SS, McInnis MG, Albert MS, Hyman BT, Tanzi RE (1998) Alpha-2 macroglobulin is genetically associated with Alzheimer disease. Nature Genetics 19(4): 357-360

Brinley AA, Theriot CA, Nelman-Gonzalez M, Crucian B, Stowe RP, Barrett AD, Pierson DL (2013) Characterization of Epstein-Barr virus reactivation in a modeled spaceflight system. Journal of Cellular Biochemistry 114(3): 616624

Calfon M, Zeng H, Urano F, Till JH, Hubbard SR, Harding HP, Clark SG, Ron D (2002) IRE1 couples endoplasmic reticulum load to secretory capacity by processing the XBP-1 mRNA. Nature 415(6867): 92-96

Chang B, Hawes NL, Hurd RE, Davisson MT, Nusinowitz S, Heckenlively JR (2002) Retinal degeneration mutants in the mouse. Vision Research 42(4): 517-525

Crousillac S, Colonna J, McMains E, Dewey JS, Gleason E (2009) Sphingosine-1-phosphate elicits receptor-dependent calcium signaling in retinal amacrine cells. Journal of Neurophysiology 102(6): 3295-3309

Cucinotta, FA, Kim MY, Willingham V, George KA (2008) Physical and biological organ dosimetry analysis for international space station astronauts. Radiation Research 170(1): 127-138

Cucinotta FA, Manuel FK, Jones J, Iszard G, Murrey J, Djojonegro B, Wear M (2001) Space radiation and cataracts in astronauts. Radiation Research 156(5): 460-466

Dalton-Griffin L, Wilson SJ, Kellam P (2009) XBox binding protein 1 contributes to induction of the Kaposi's Sarcoma-associated herpesvirus lytic cycle under hypoxic conditions. Journal of Virology 83(14): 72027209

Daum G, Grabski A, Reidy MA (2009) Sphingosine 1-phosphate: a regulator of arterial lesions. Arteriosclerosis, Thrombosis, and Vascular Biology 29(10): 1439-1443
Deng X, Shibata H, Takeuchi N, Rachi S, Sakai M, Ninomiya H, Iwata N, Ozaki N, Fukumaki Y (2007) Association study of polymorphisms in the glutamate transporter genes SLC1A1, SLC1A3, and SLC1A6 with schizophrenia. American Journal of Medical Genetics Part B: Neuropsychiatric Genetics 144B(3): 271278

Eichmann A, Makinen T, Alitalo K (2005) Neural guidance molecules regulate vascular remodeling and vessel navigation. Genes \& Development 19(9): 1013-1021

Guzel E, Basar M, Ocak N, Arici A, Kayisli UA (2011) Bidirectional interaction between unfolded-protein-response key protein HSPA5 and estrogen signaling in human endometrium. Biology of Reproduction 85(1): 121-127

Hadziahmetovic M, Pajic M, Grieco S, Song Y, Song D, Li Y, Cwanger A, Lacovelli J, Chu S, Ying G, Connelly J, Spino M, Dunaief JL (2012) The oral iron chelator deferiprone protects against retinal degeneration induced through diverse mechanisms. Translational Vision Science \& Technology 1(3): 2

Hebert DN, Molinari M (2007) In and out of the ER: protein folding, quality control, degradation, and related human diseases. Physiological Reviews 87(4): 1377-1408

Hsu WC, Wand HK, Lee LC, Fung HC, Lin JC, Hsu JP, Wu YR, Ro LS, Hu FJ, Chang YT, Lee-Chen GJ, Chen CM (2008) Promoter polymorphisms modulating HSPA5 expression may increase susceptibility to Taiwanese Alzheimer's disease. Journal of Neural Transmission 115(11): 1537-1543

Kramer LA, Sargsyan AE, Hasan KM, Polk JD, Hamilton DR (2012) Orbital and intracranial effects of microgravity: findings at 3-T MR imaging. Radiology 263(3): 819-827

Lawson WE, Crossno PF, Plosukhin VV, Roldan J, Cheng D, Lane KB, Blackwell TR, Xu C, Markin C, Ware LB, Miller GG, Loyd JE, Blackwell TS (2008) Endoplasmic reticulum stress in alveolar epithelial cells is prominent in IPF: association with altered surfactant protein processing and herpesvirus infection. American Journal of Physiology - Lung Cellular and Molecular Physiology 294(6): 1119-1126 
Lee K, Tirasophon W, Shen X, Michalak M, Prywes R, Okada T, Yoshida H, Mori K, Kaufman RJ (2002) IRE1-mediated unconventional mRNA splicing and S2Pmediated ATF6 cleavage merge to regulate $\mathrm{XBP} 1$ in signaling the unfolded protein response. Genes \& Development 16(4): 452466

Lee T, Luo L (1999) Mosaic analysis with a repressible cell marker for studies of gene function in neuronal morphogenesis. Neuron 22(3): 451-461

Liao A, Nitsch RM, Greenberg SM, Finckh U, Blacker D, Albert M, Rebeck GW, Govez-Isla R, Clatworthy A, Binetti G, Hock C, MuellerThomsen T, Mann U, Zuckowski K, Beisiegel U, Staehelin H, Growdon JH, Tanzi RE, Hyman BT (1998) Genetic association of an a2-macroglobulin (Val10001le) polymorphism and Alzheimer's disease. Human Molecular Genetics 7(12): 1953-1956

Mader TH, Gibson CR, Pass AF, Kramer LA, Lee AG, Fogarty J, Tarver WJ, Dervay JP, Hamilton DR, Sargsyan A, Phillips JL, Tran D, Lipsky W, Choi J, Stern C, Kuyumjian R, Polk JD (2011) Optic disc edema, globe flattening, choroidal folds, and hyperopic shifts observed in astronauts after longduration space flight. Ophthalmology 118(10): 2058-2069

Mader TH, Koch DD, Manuel K, Gibson CR, Effenhauser RK, Musgrave S (1999) Stability of vision during space flight in an astronaut with bilateral intraocular lenses. American Journal of Ophthalmology 127(3): 342-343

Mandela P, Yankova M, Conti LH, Ma X, Grady J, Eipper BA, Mains RE (2012) Kalrn plays key roles within and outside of the nervous system. BMC Neuroscience 13(1): 136

Mao XW, Pecaut MJ, Stodieck LS, Ferguson VL, Bateman TA, Bouxsein M, Jones TA, Moldovan M, Cunningham CE, Chieu J, Gridley DS (2013) Spaceflight environment induces mitochondrial oxidative damage in ocular tissue. Radiation Research 180(4): 340-350

Marshall-Bowman K, Barratt MR, Gibson CR (2013) Ophthalmic changes and increased intracranial pressure associated with long duration spaceflight: an emerging understanding. Acta Astronautica 87: 77-87
Martins RAP, Linden R, Dyer MA (2006) Glutamate regulates retinal progenitors cells proliferation during development. European Journal of Neuroscience 24(4): 969-980

Mehta, SK, Cohrs RJ, Forghani B, Zerbe G, Gilden DH, Pierson DL (2004) Stress-induced subclinical reactivation of varicella zoster virus in astronauts. Journal of Medical Virology 72(1): 174-179

Mehta SK, Stowe RP, Feiveson AH, Tyring SK, Pierson DL (2000) Reactivation and shedding of cytomegalovirus in astronauts during spaceflight. Journal of Infectious Diseases 182(6): 1761-1764

Naidu S, Winget CM, Jenner JW, Mele G, Holley DC (1995) Effects of housing density on mouse physiology and behavior in the NASA animal enclosure module simulators. Journal of Gravitational Physiology 2(1): 140

Nakagawa T, Zhu H, Morishima N, Li E, Xu J, Yankner BA, Yuan J (2000) Caspase-12 mediates endoplasmic-reticulum-specific apoptosis and cytotoxicity by amyloid- $\beta$. Nature 403(6765): 98-103

Park J, Choi K, Kim S, Kim K (2003) Coordinated interaction of the vascular and nervous systems: from molecule- to cell-based approaches. Biochemical and Biophysical Research Communications 311(2): 247-253

Philpott DE, Corbett R, Turnbill C, Black S, Dayhoff D, McGourty J, Lee R, Harrison G, Savick L (1980) Retinal changes in rats flown on Cosmos 936: a cosmic ray experiment. Aviation, Space, and Environmental Medicine 51(6): 556-562

Pietsch J, Bauer J, Egli M, Infanger M, Wise P, Ulbrich C, Grimm D (2011) The effects of weightlessness on the human organism and mammalian cells. Current Molecular Medicine 11(5): 350-364

Planel H, Gaubin Y, Pianezzi B, Gasset G (1989) Space environmental factors affecting responses to radiation at the cellular level. Advances in Space Research 9(10): 157-160

Reitz G, Berger T, Bilski P, Facius R, Hajek M, Petrov V, Puchalska M, Zhou D, Bossler J, Akatov Y, Shurshakov V, Olko P, Ptaszkiewicz $M$, Bergmann R, Fugger $M$, Vana N, Beaujean R, Burmeister S, Bartlett D, Hager L, Palfalvi J, Szabo J, O'Sullivan D, Kitamura H, Uchihori Y, Yasuda N, 
Nagamatsu A, Tawara H, Benton E, Gaza R, McKeever S, Sawakuchi G, Yukihara E, Cucinotta FA, Semones E, Zapp N, Miller J, Dettmann J (2009) Astronaut's organ doses inferred from measurements in a human phantom outside the International Space Station. Radiation Research 171(2): 225-235

Sanchez T, Skoura A, Wu MT, Casserly B, Harrington EO, Hla T (2007) Induction of vascular permeability by the sphingosine-1phosphate receptor-2 (S1P2R) and its downstream effectors ROCK and PTEN. Arteriosclerosis, Thrombosis, and Vascular Biology 27(6): 1312-1318

Sheldon AL, Robinson MB (2007) The role of glutamate transporters in neurodegenerative diseases and potential opportunities for intervention. Neurochemistry International 51(6-7): 333-355

Sides MB, Vernikos J, Convertino VA, Stepanek J, Tripp LD, Draeger J, Hargens AR, Kourtidou-Papadeli C, Pavy-LeTraon A, Russomano T, Wong J, Buccello RR, Lee PH, Nangalia V, Saary JM (2005) The Bellagio Report: cardiovascular risks of spaceflight: implications for the future of space travel. Aviation, Space, and Environmental Medicine 76(9): 877-895

Song D, Song Y, Hadziahmetovic M, Zhong Y, Dunaief JL (2012) Systemic administration of the iron chelator deferiprone protects against light-induced photoreceptor degeneration in the mouse retina. Free Radical Biology and Medicine 53(1): 64-71

Sonnenfeld G, Butel JS, Shearer WT (2003) Effects of the spaceflight environment on the immune system. Reviews on Environmental Health 18(1): 1-18

Sriburi R, Jackowski S, Mori K, Brewer JW (2004) XBP1 a link between the unfolded protein response, lipid biosynthesis, and biogenesis of the endoplasmic reticulum. The Journal of Cell Biology 167(1): 35-41

Stowe RP, Mehta SK, Ferrando AA, Feeback DL, Pierson DL (2001) Immune responses and latent herpesvirus reactivation in spaceflight. Aviation, Space, and Environmental Medicine 72(10): 884-891

Suchting S, Bicknell R, Eichmann A (2006) Neuronal clues to vascular guidance. Experimental Cell Research 312(5): 668-675
Sundaresan A, Pellis NR (2009) Cellular and genetic adaptation in low-gravity environments. Annals of the New York Academy of Sciences 1161(1): 135-146

Szegezdi E, Fitzgerald U, Samali A (2003) Caspase-12 and ER-stress-mediated apoptosis. Annals of the New York Academy of Sciences 1010(1): 186-194

Taibbi G, Cromwell RL, Kapoor KG, Godley BF, Vizzeri G (2013) The effect of microgravity on ocular structures and visual function: a review. Survey of Ophthalmology 58(2): 155163

Taylor CR, Hanna M, Behnke BJ, Stabley JN, McCullough DJ, Davis RT, Ghosh P, Papadopoulos A, Muller-Delp JM, Delp MD (2013) Spaceflight-induced alterations in cerebral artery vasoconstrictor, mechanical, and structural properties: implications for elevated cerebral perfusion and intracranial pressure. The FASEB Journal 27(6): 22822292

Tombran-Tink J, Barnstable CJ (2006) Spaceflight environment induces degeneration in the retina of rat neonates. Retinal Degenerative Diseases - Advances in Experimental Medicine and Biology 572: 417-424

Whelan JP, McGinnis JF (1988) Light-dependent subcellular movement of photoreceptor proteins. Journal of Neuroscience Research 20(2): 263-270

Wilson SJ, Tsao EH, Webb BLJ, Ye H, DaltonGriffin L, Tsantoulas C, Gale CV, Du M, Whitehouse A, Kellam P (2007) X box binding protein XBP-1s transactivates the Kaposi's Sarcoma-associated herpesvirus (KSHV) ORF50 promoter, linking plasma cell differentiation to KSHV reactivation from latency. Journal of Virology 81(24): 1357813586

Zanello S, Theriot CA, Prospero-Ponce C, Chevez-Barrios P (2013) Spaceflight effects and molecular responses in the mouse eye: preliminary observations after shuttle mission STS-133. Gravitational and Space Research 1(1): $30-46$ 


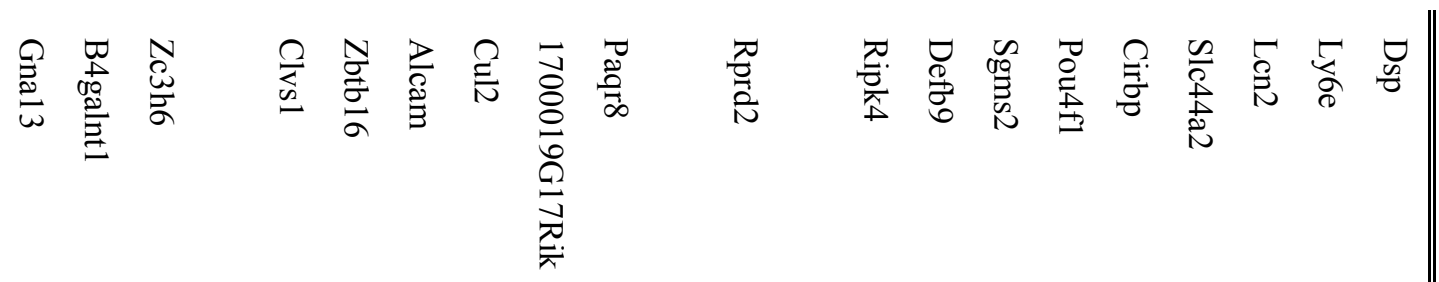

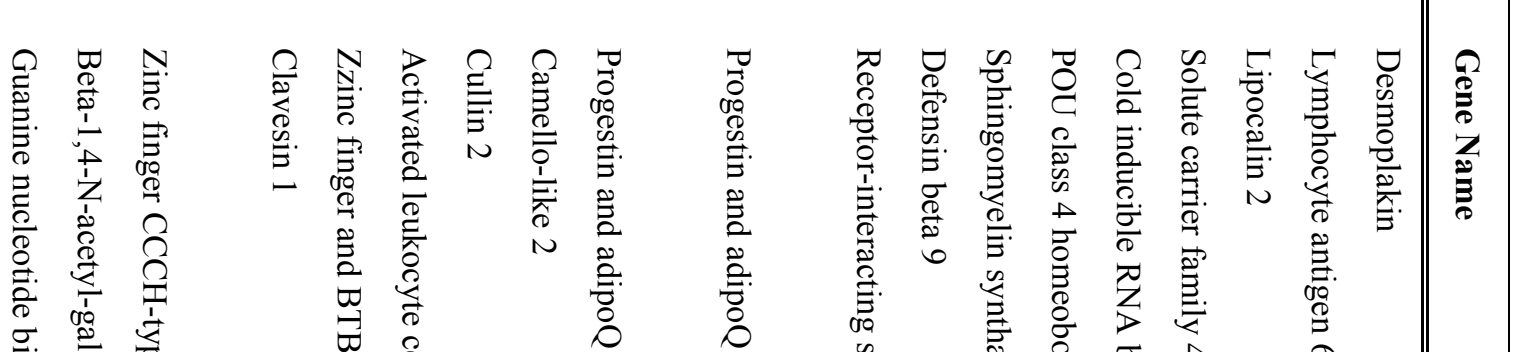

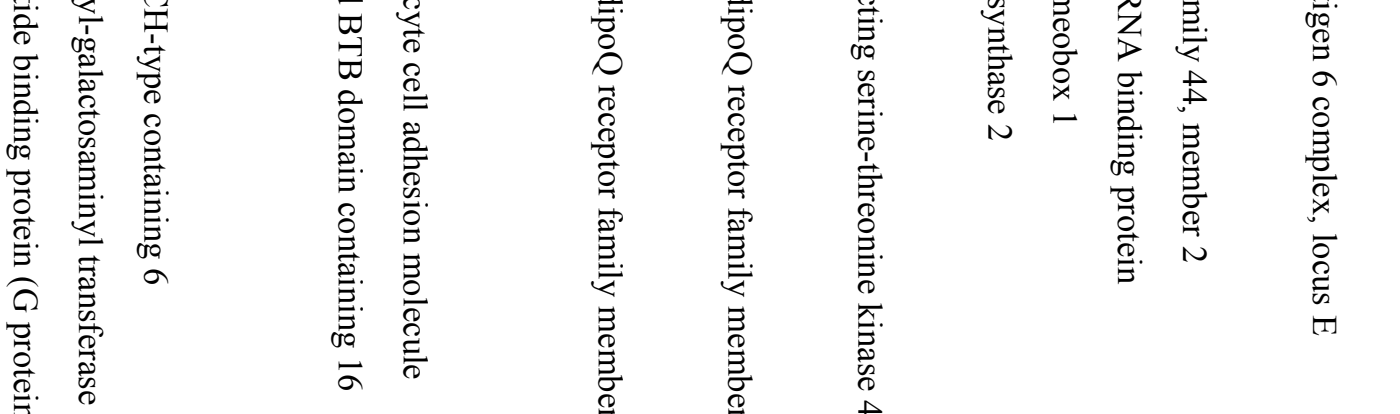

这.

营

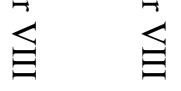

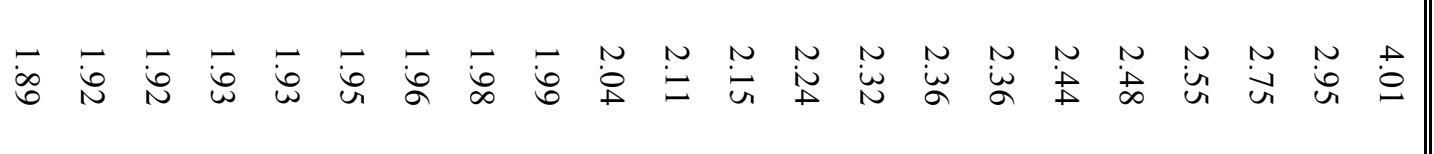

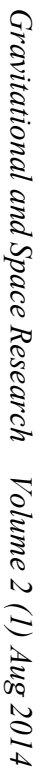

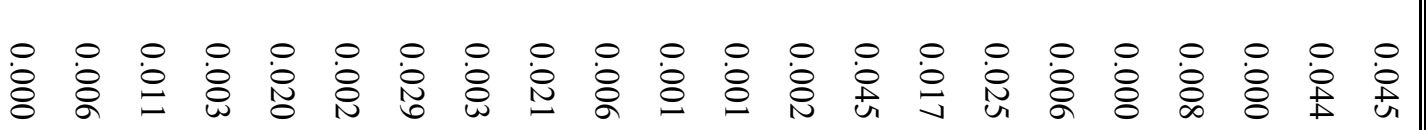

w

\begin{tabular}{l|}
0 \\
0 \\
0 \\
0 \\
ñ \\
Ẽ \\
E
\end{tabular}

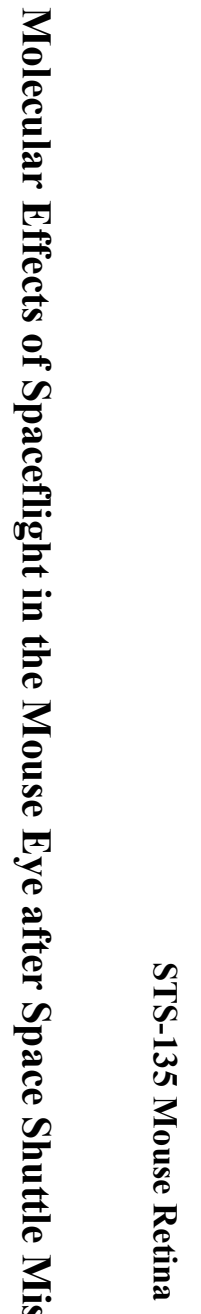

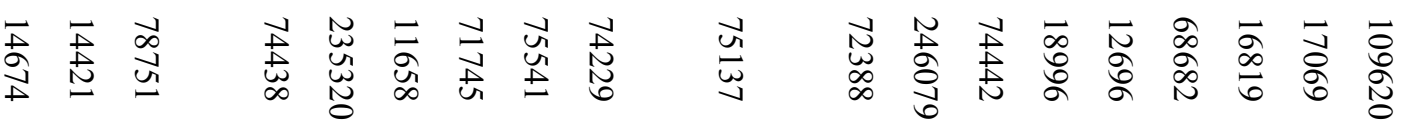

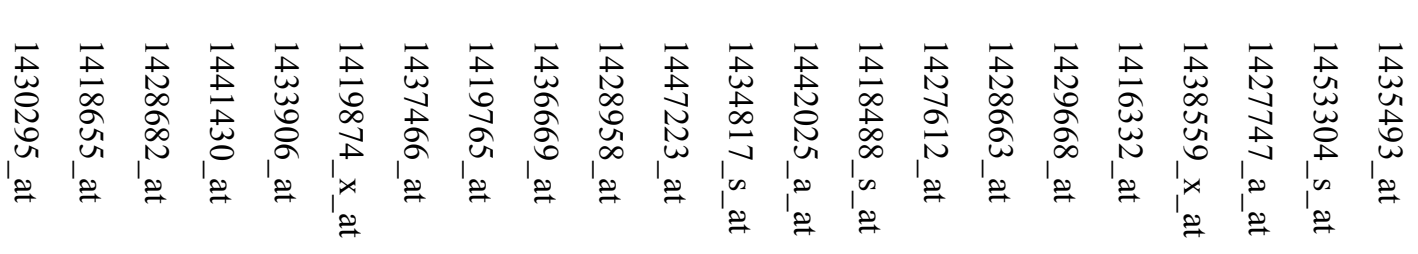




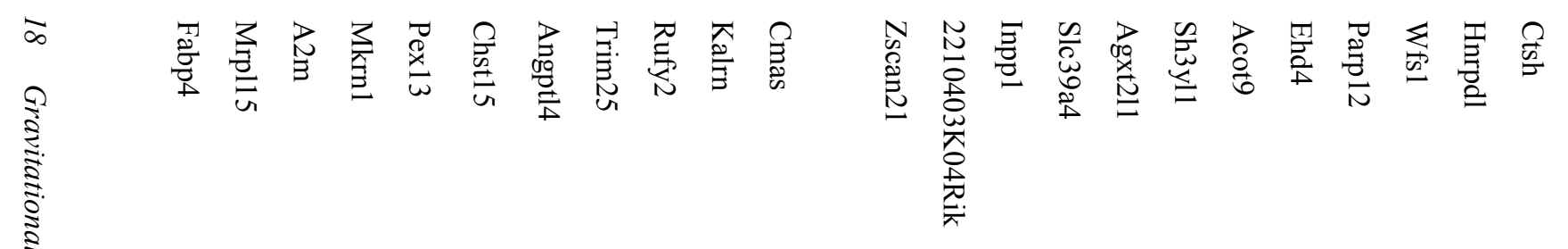

$\$$
0
0
0
0
0
0
$\vdots$
$\vdots$

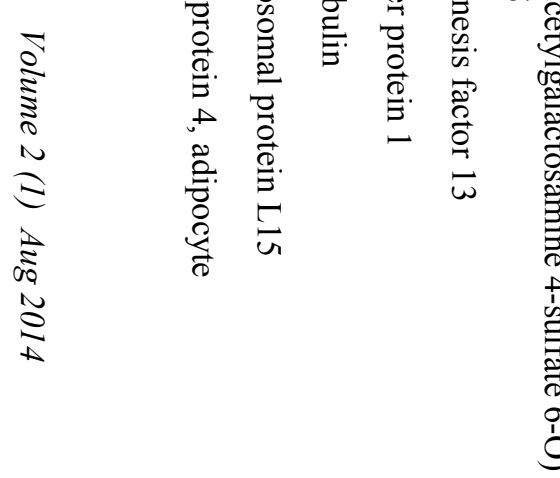
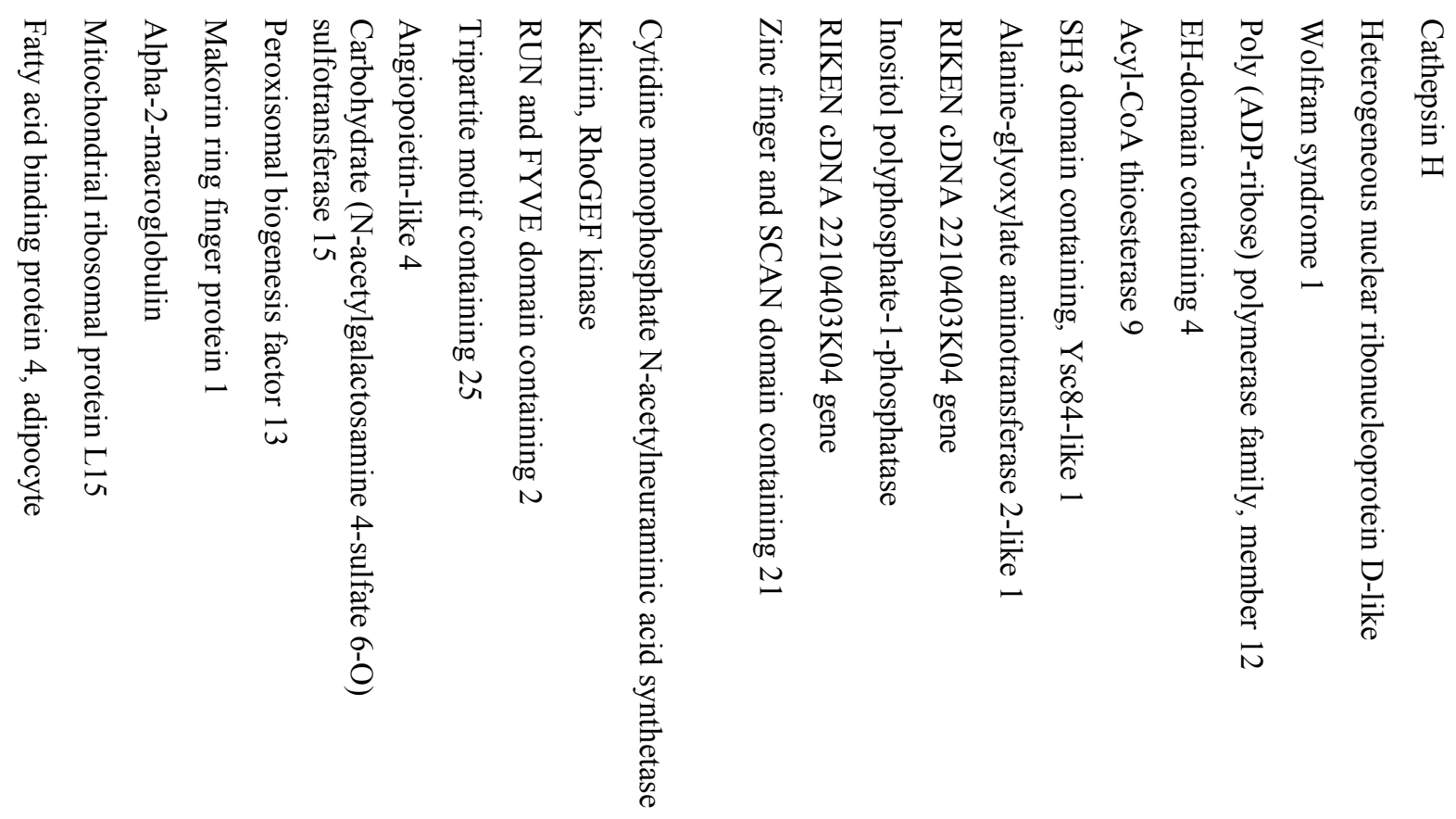

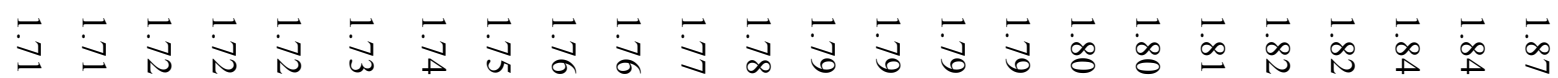

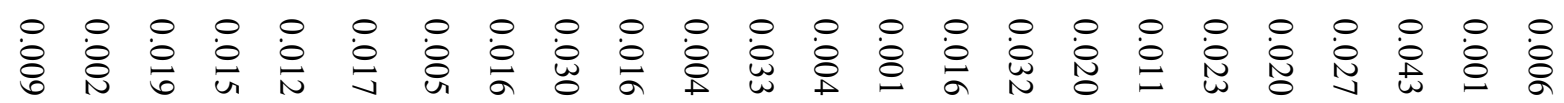

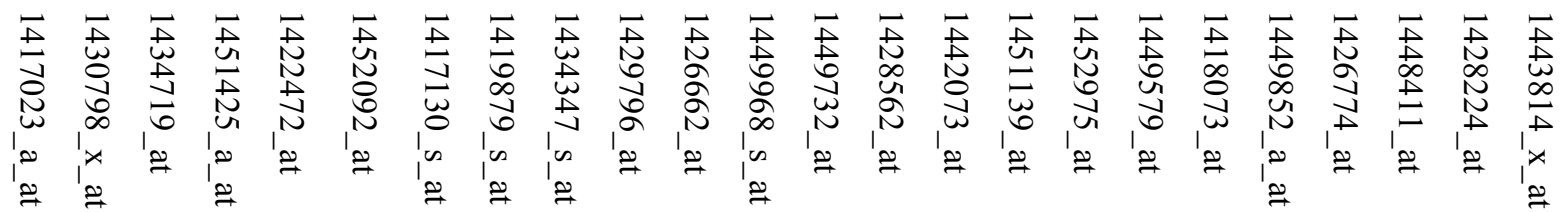

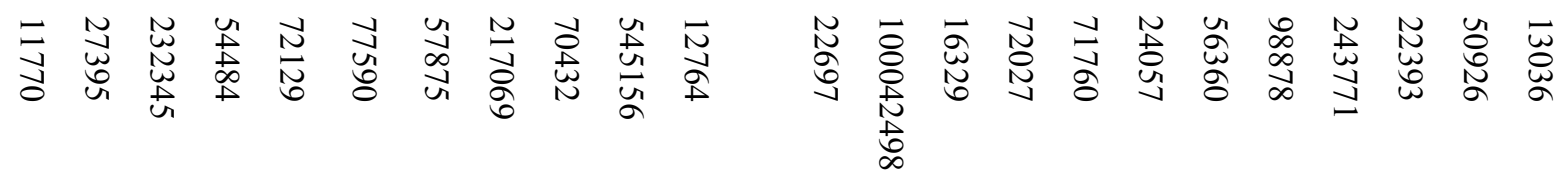




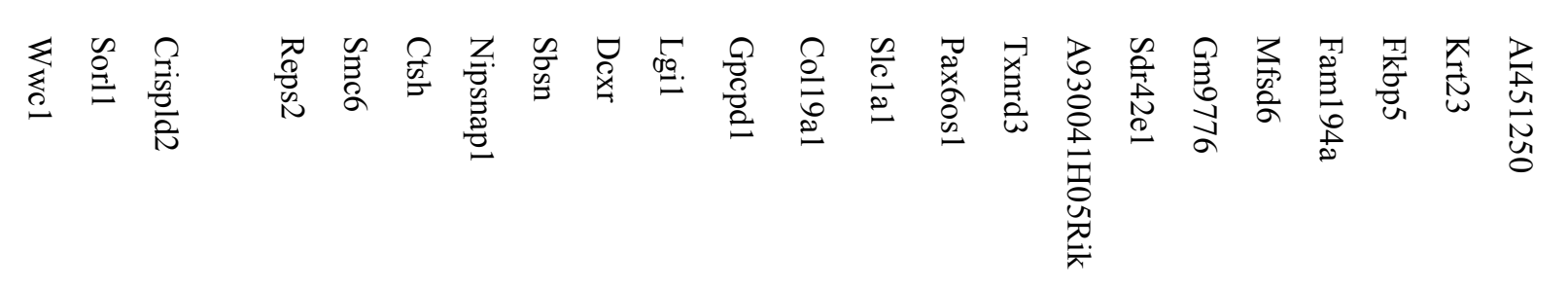

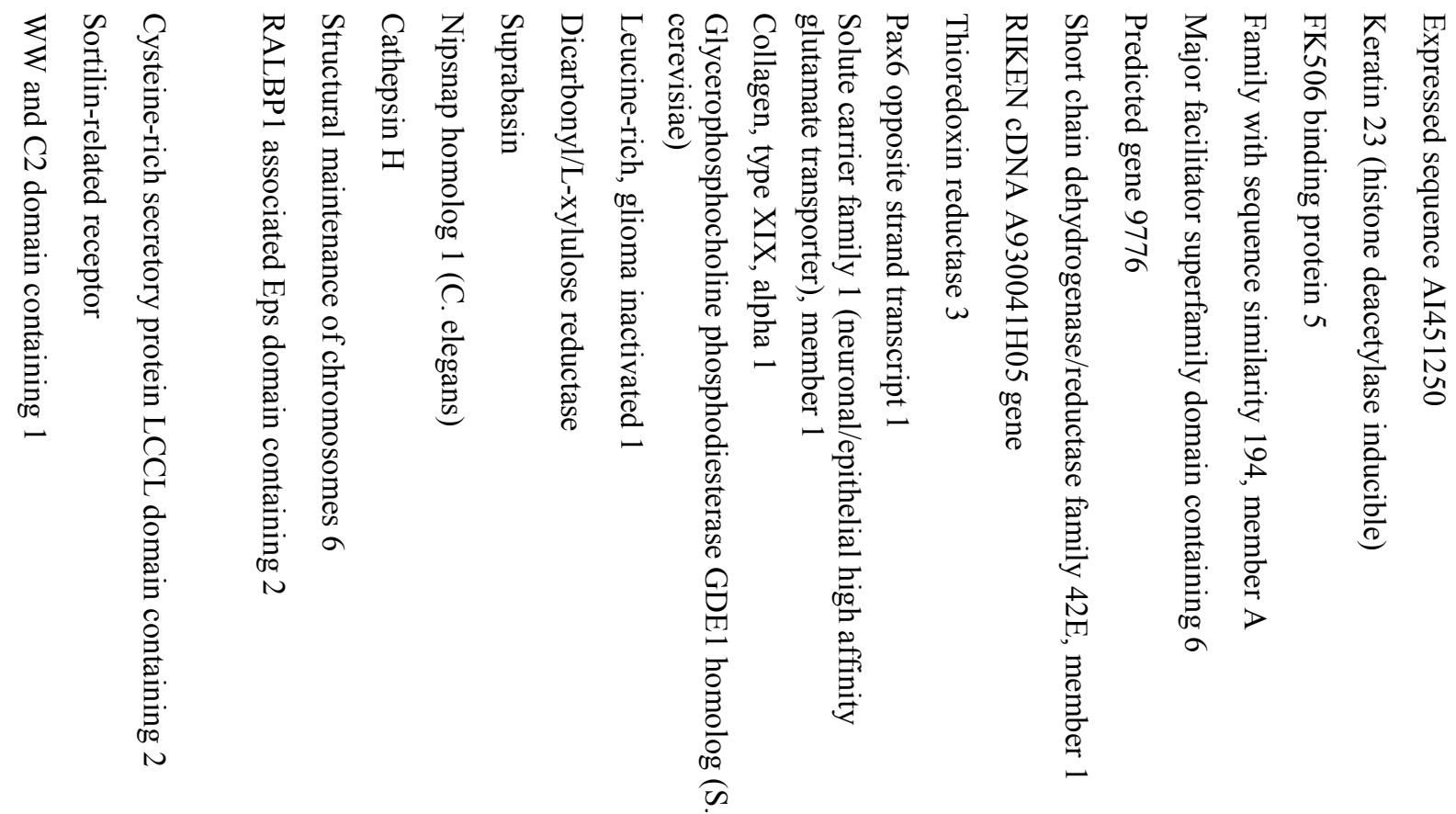

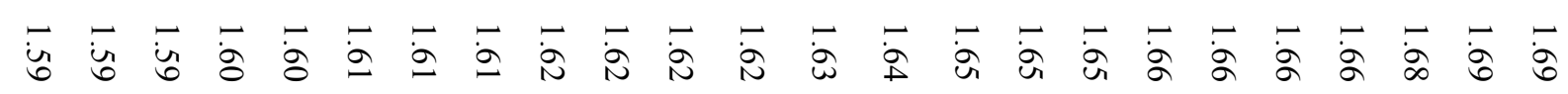

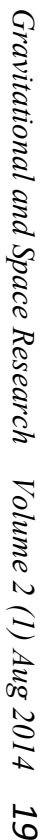

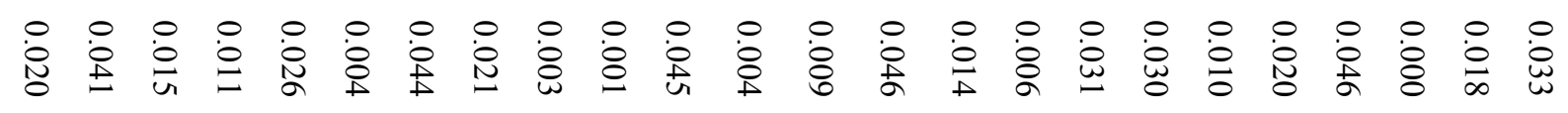

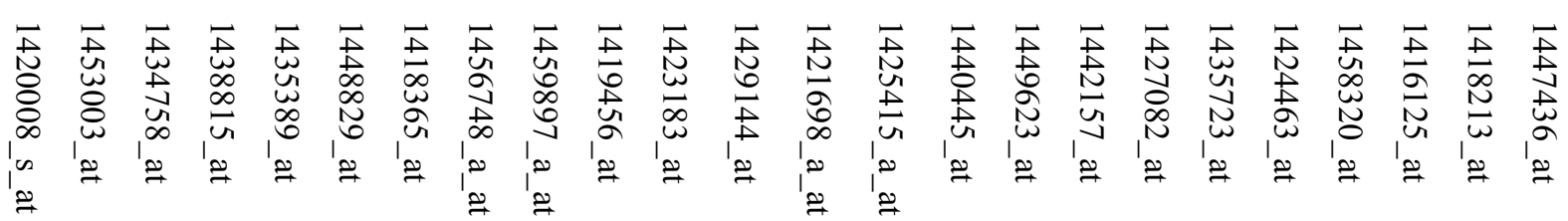

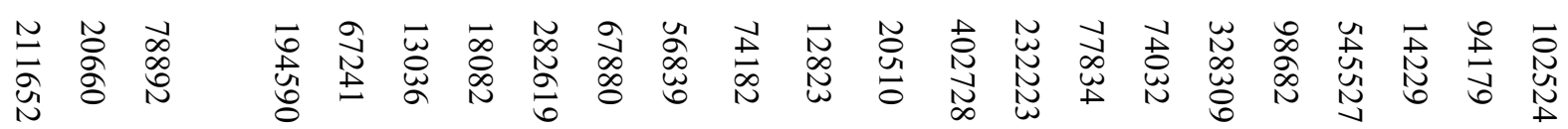




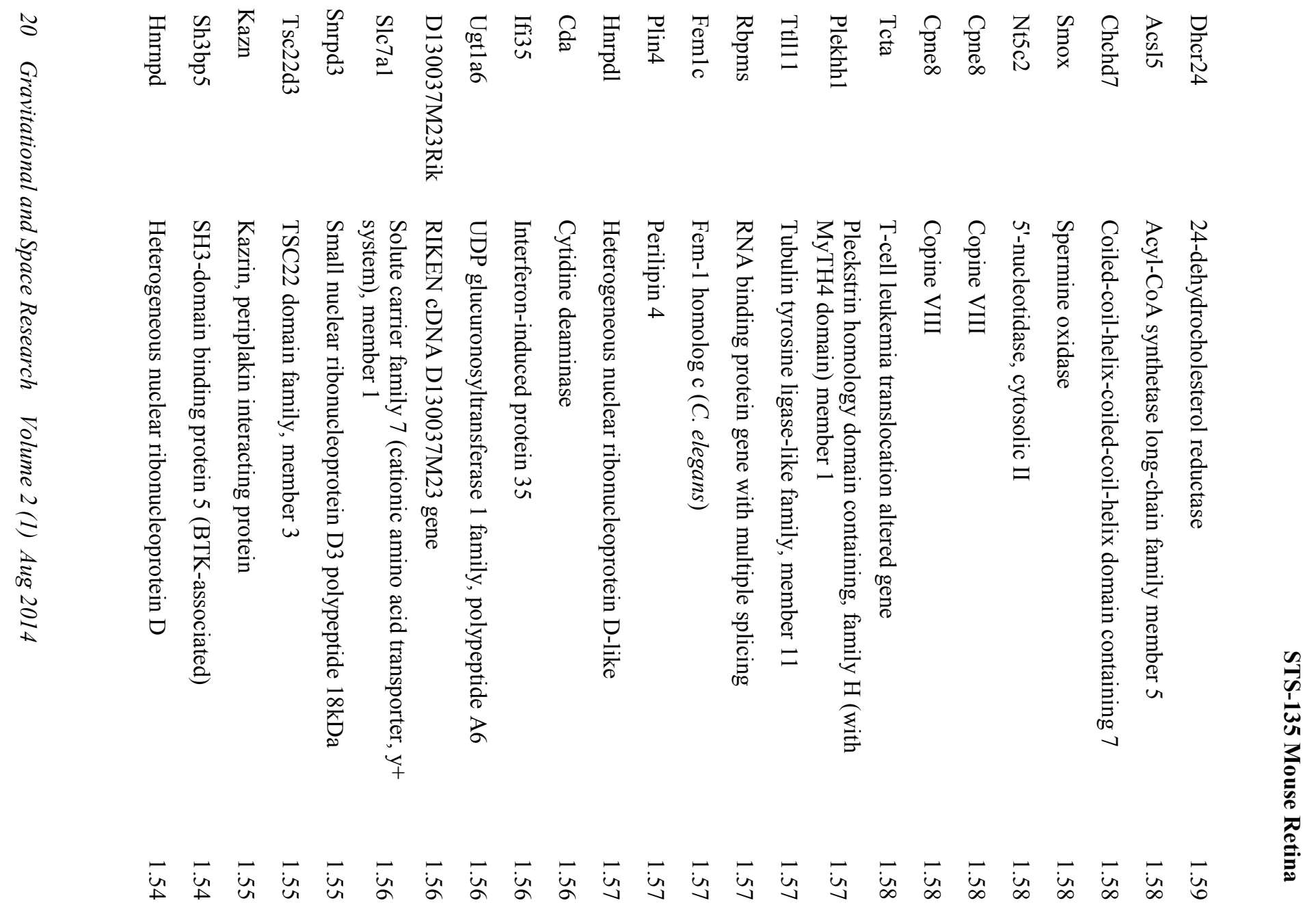

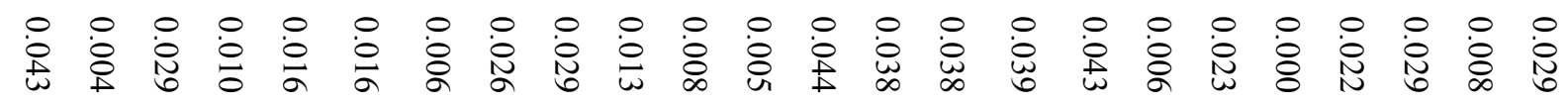

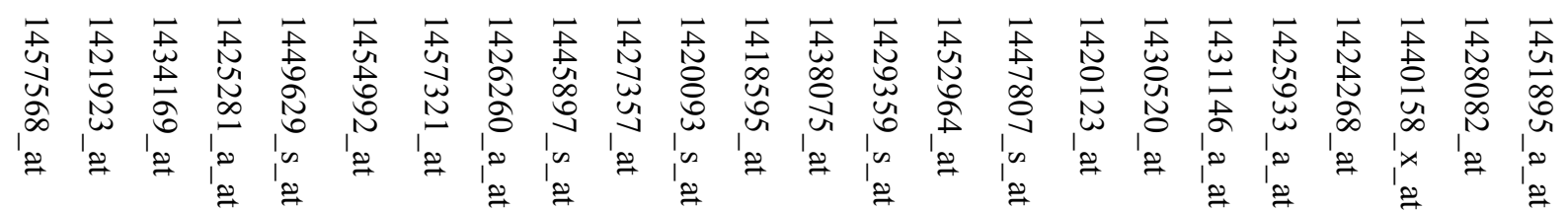

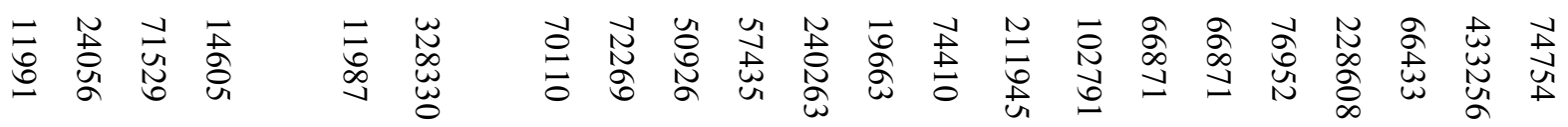




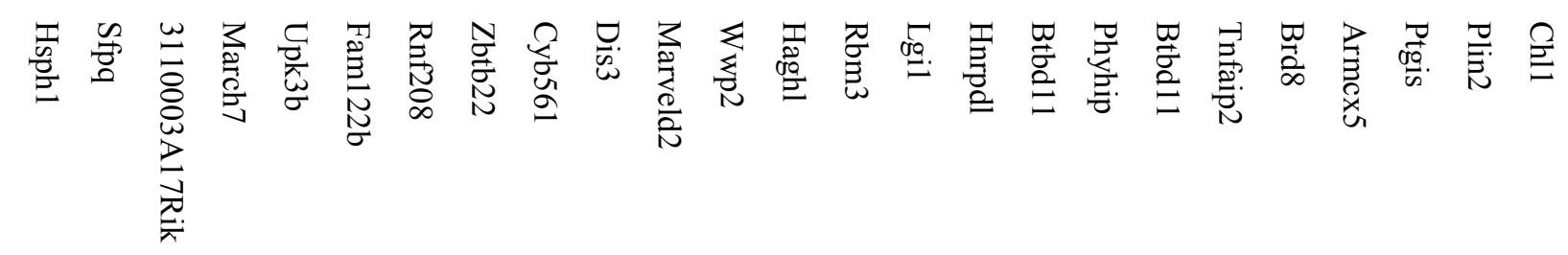

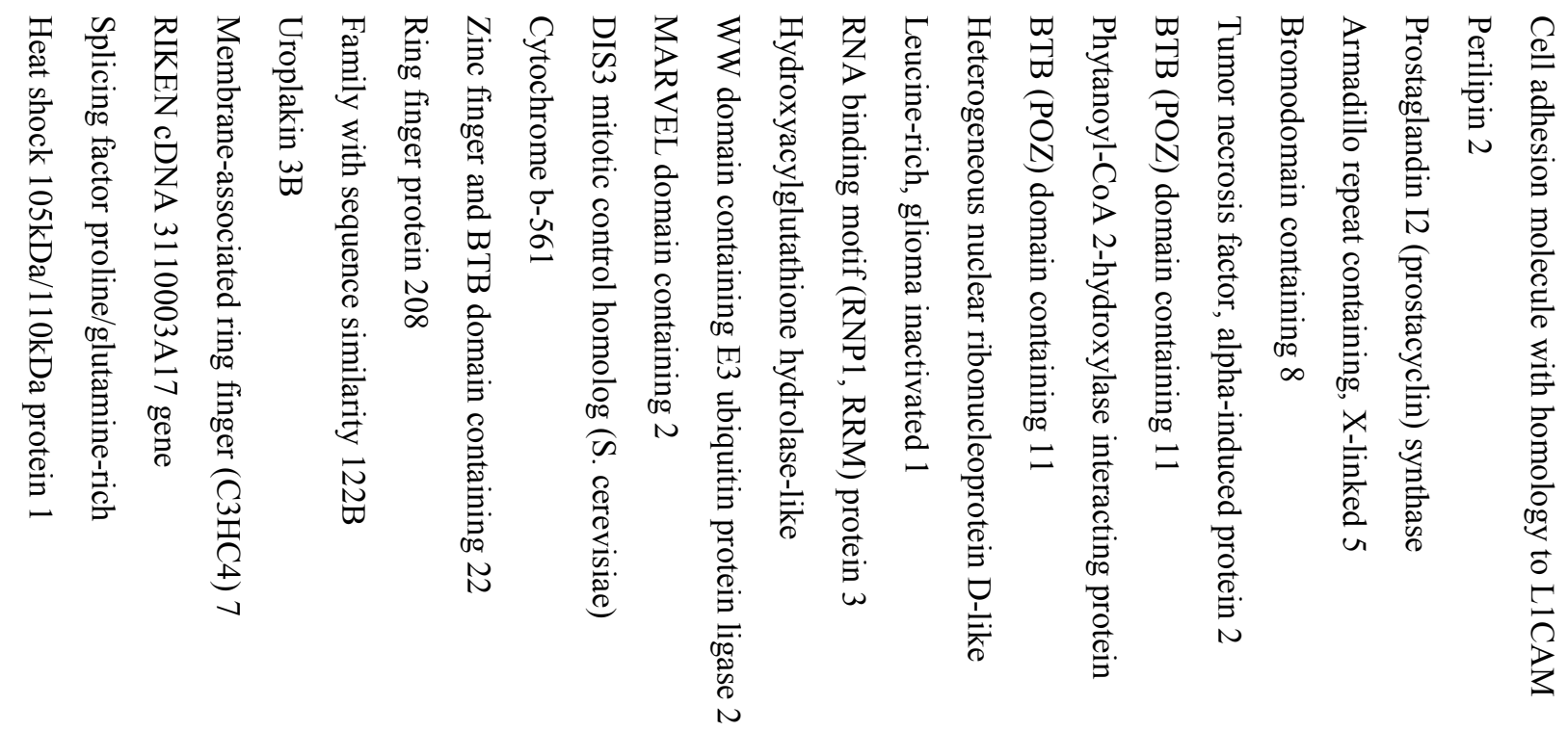

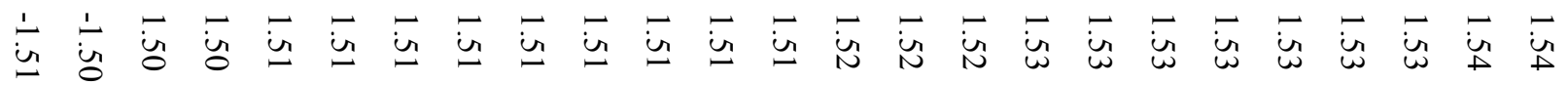

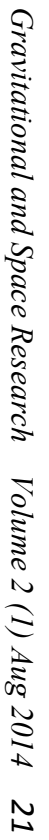

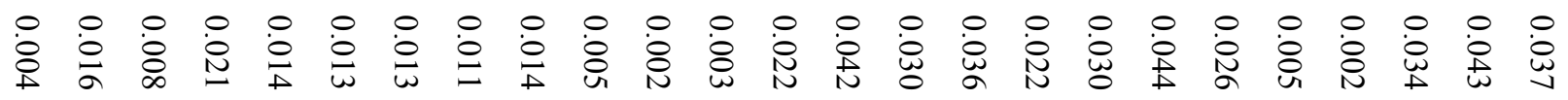

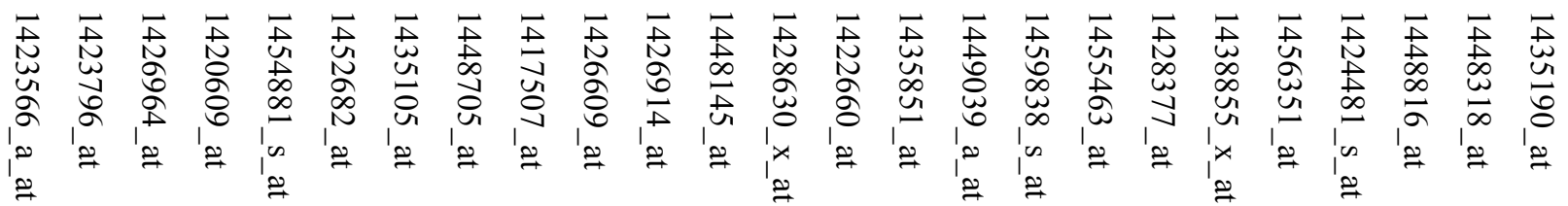

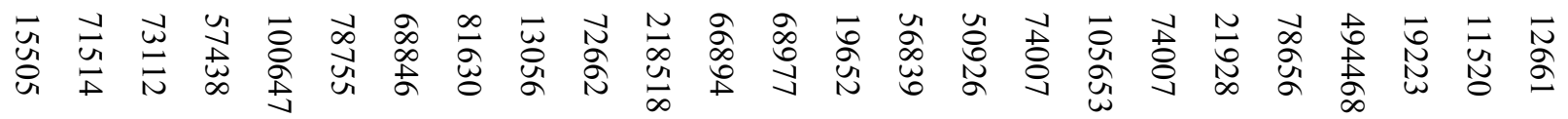




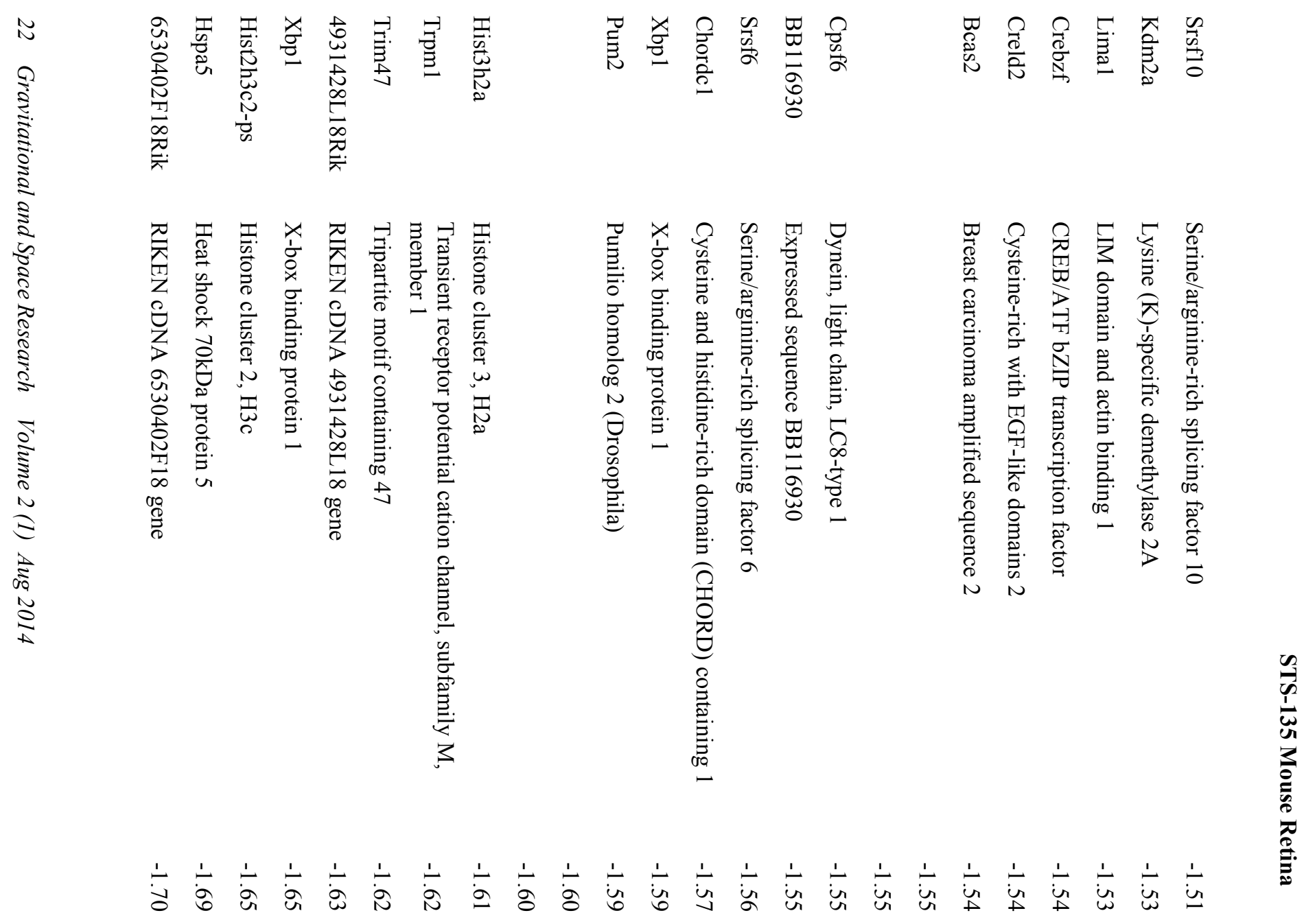

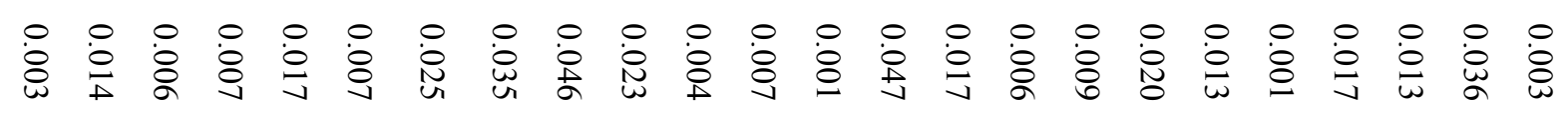

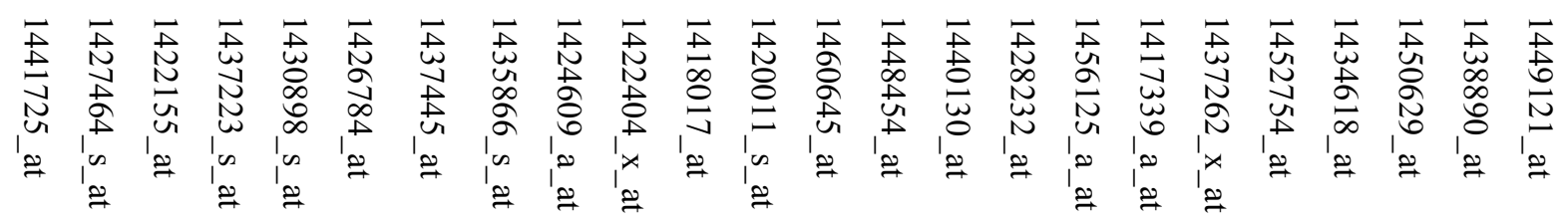

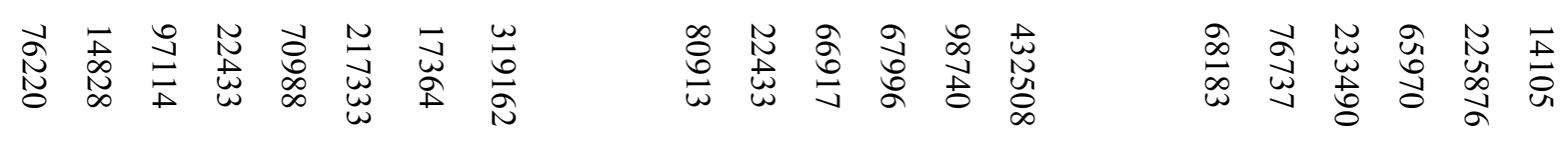




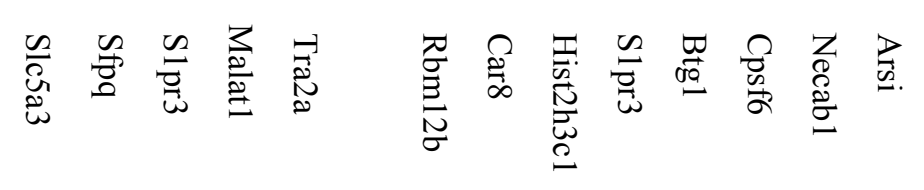

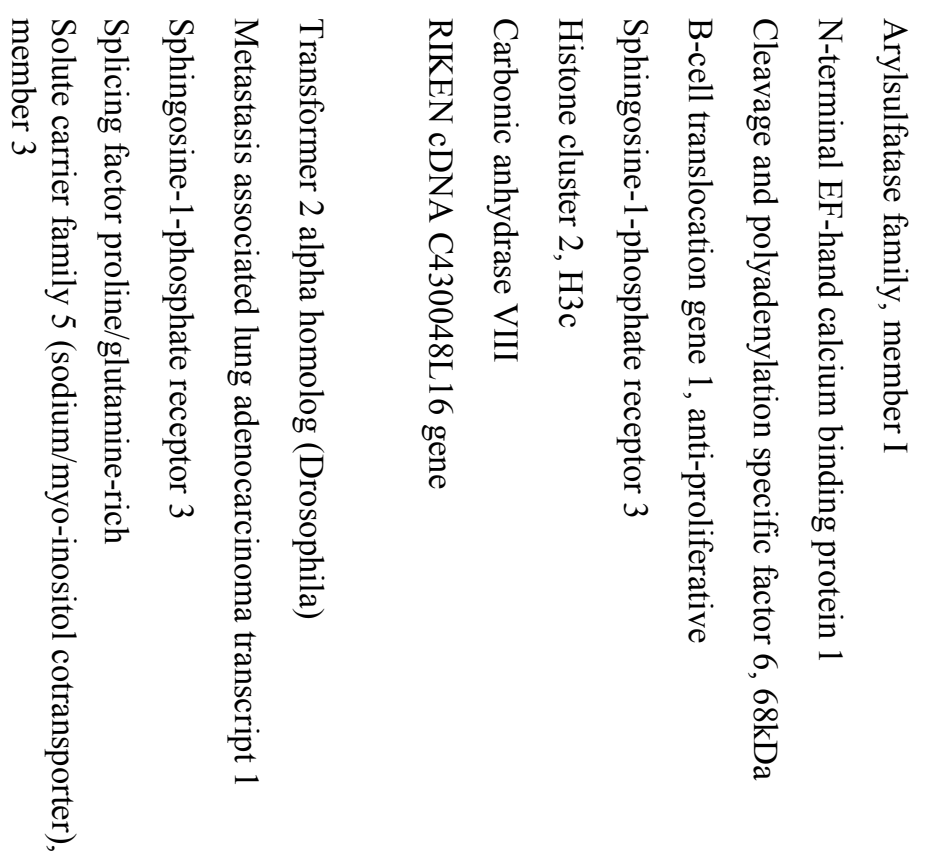

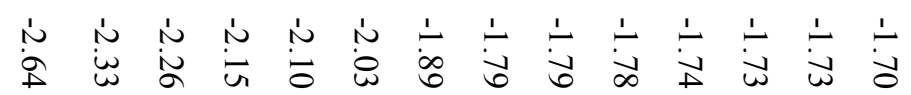

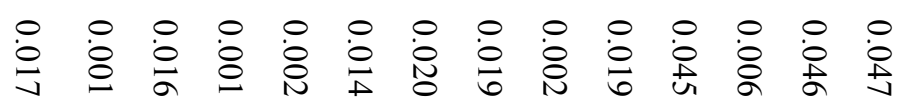

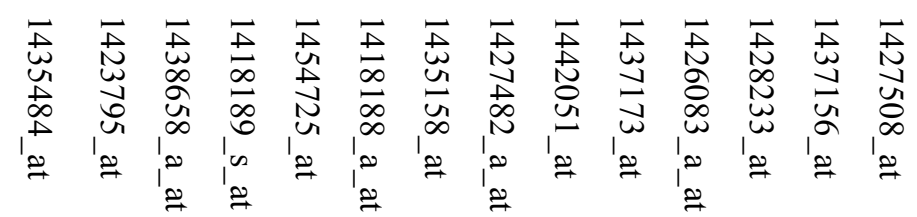

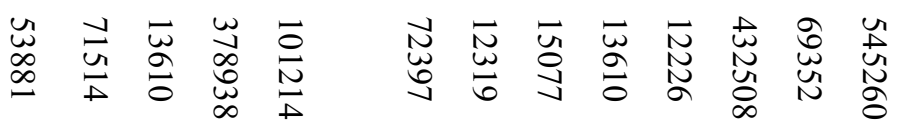




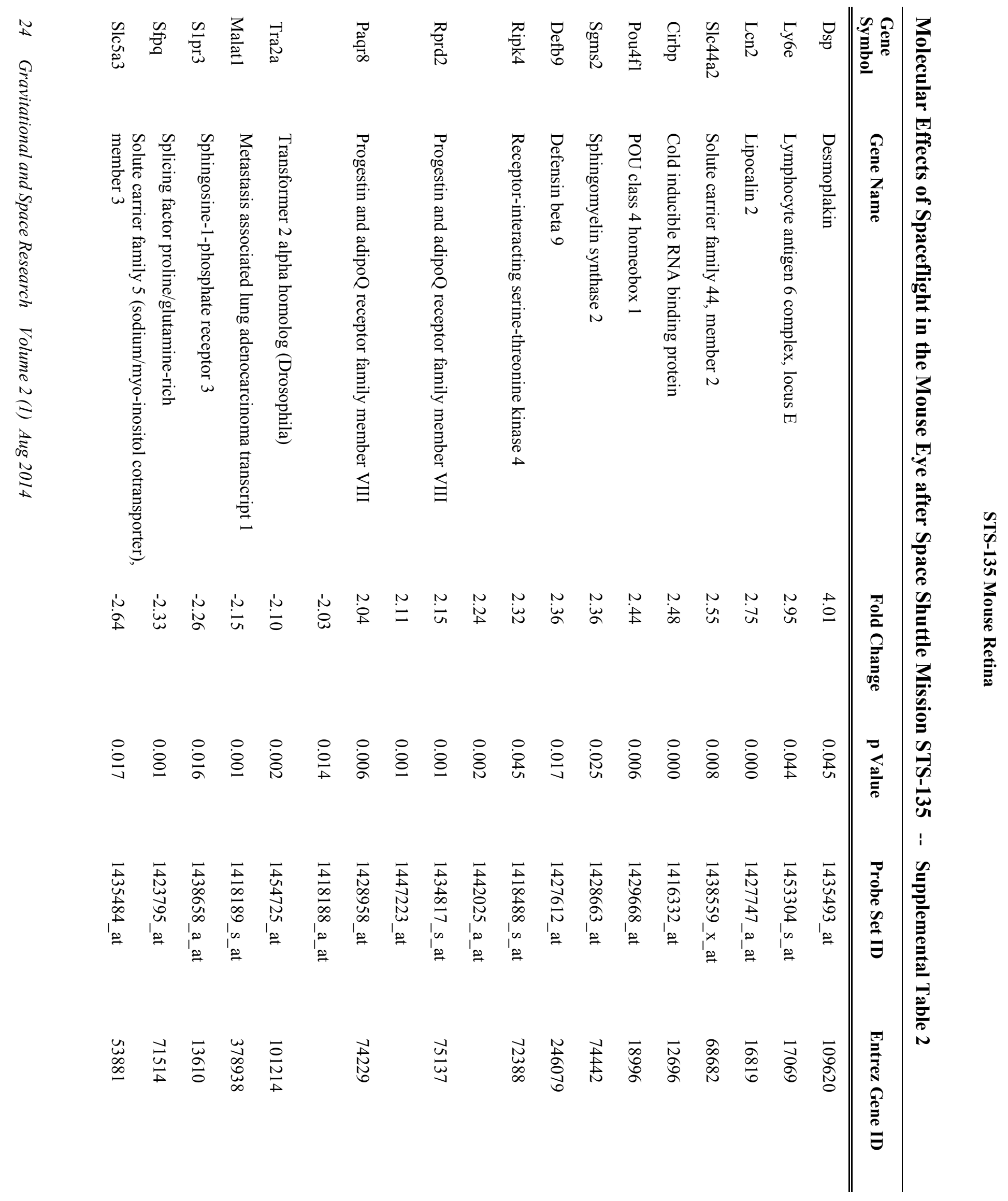

